\title{
Treatment of SRS Tank 48H Simulants Using Fenton's Reagent
}

November 2003

Prepared by

P. A. Taylor 


\title{
DOCUMENT AVAILABILITY
}

Reports produced after January 1, 1996, are generally available free via the U.S. Department of Energy (DOE) Information Bridge.

\section{Web site http://www.osti.gov/bridge}

Reports produced before January 1, 1996, may be purchased by members of the public from the following source.

\author{
National Technical Information Service \\ 5285 Port Royal Road \\ Springfield, VA 22161 \\ Telephone 703-605-6000 (1-800-553-6847) \\ TDD 703-487-4639 \\ Fax 703-605-6900 \\ E-mail omfp@mtos/fedwpr;d/gpv \\ Web site http://www.ntis.gov/support/ordemowabout.htm
}

Reports are available to DOE employees, DOE contractors, Energy Technology Data Exchange (ETDE) representatives, and International Nuclear Information System (INIS) representatives from the following source.

Office of Scientific and Technical Information

P.O. Box 62

Oak Ridge, TN 37831

Telephone 865-576-8401

Fax 865-576-5728

E-mail reports@adonis.osti.gov

Web site http://www.osti.gov/contact.html

\begin{abstract}
This report was prepared as an account of work sponsored by an agency of the United States Government. Neither the United States government nor any agency thereof, nor any of their employees, makes any warranty, express or implied, or assumes any legal liability or responsibility for the accuracy, completeness, or usefulness of any information, apparatus, product, or process disclosed, or represents that its use would not infringe privately owned rights. Reference herein to any specific commercial product, process, or service by trade name, trademark, manufacturer, or otherwise, does not necessarily constitute or imply its endorsement, recommendation, or favoring by the United States Government or any agency thereof. The views and opinions of authors expressed herein do not necessarily state or reflect those of the United States Government or any agency thereof.
\end{abstract}


Nuclear Science and Technology Division

\title{
TREATMENT OF SRS TANK 48H SIMULANTS USING FENTON'S REAGENT
}

\author{
P. A. Taylor
}

Date Published: November 2003

\author{
Prepared by \\ OAK RIDGE NATIONAL LABORATORY \\ P.O. Box 2008 \\ Oak Ridge, Tennessee 37831-6283 \\ managed by \\ UT-BATTELLE, LLC \\ for the \\ U.S. DEPARTMENT OF ENERGY \\ under contract DE-AC05-00OR22725
}





\section{CONTENTS}

Page

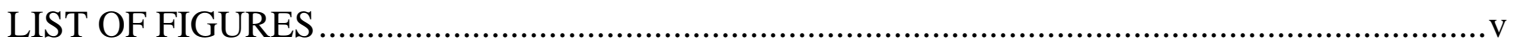

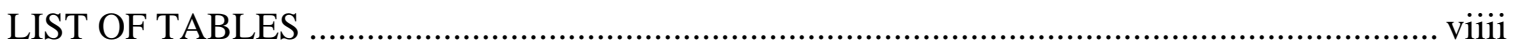

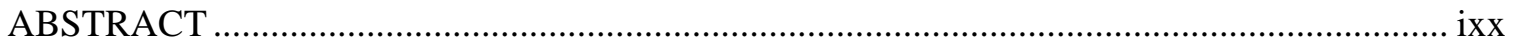

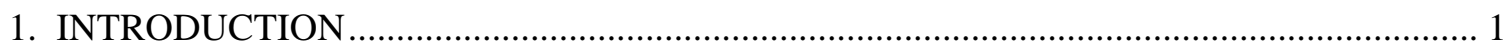

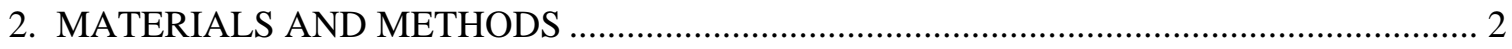

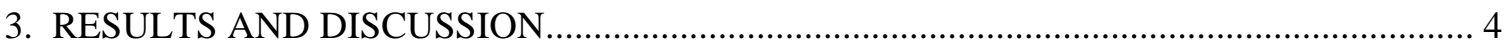

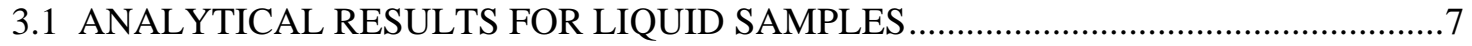

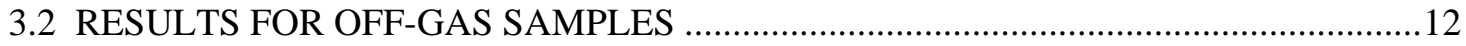

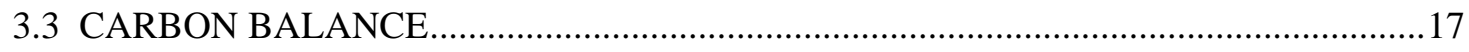

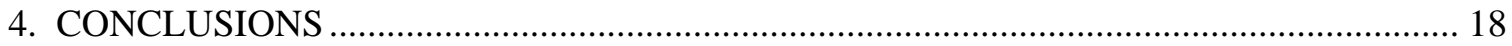

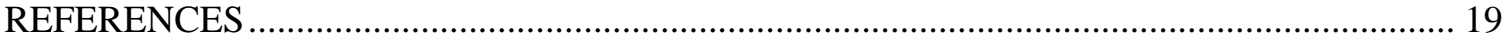





\section{LIST OF FIGURES}

Figure

Page

1 Test set up for treating Tank 48 simulants......................................................................................... 3

2 Treatment sequence for test 5 , plus views of condenser and off-gas ...................................................... 5

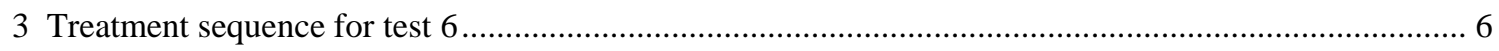

4 Total organic carbon concentrations of slurries during treatment. ........................................................ 8

5 Settling rates for treated simulant slurries ................................................................................... 11

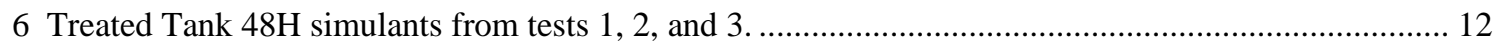

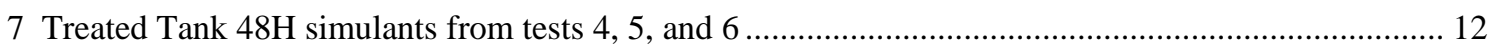

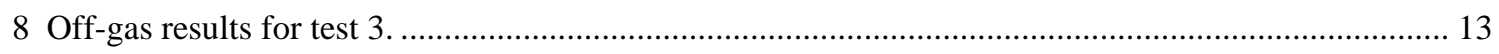

9 Major constituents in gas from test 4, measured by gas chromatography. ............................................. 14

10 Major constituents in gas from test 5, measured by gas chromatography .............................................. 15

11 Major constituents in gas from test 6, measured by gas chromatography ............................................. 15

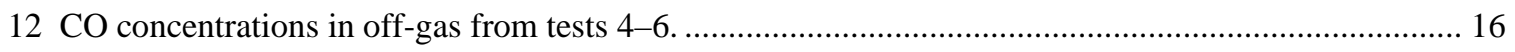

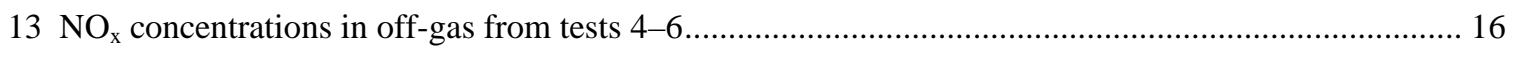

14 Benzene concentrations in off-gas samples, measured by gas chromatography-mass spectroscopy ..... 17 



\section{LIST OF TABLES}

Table

Page

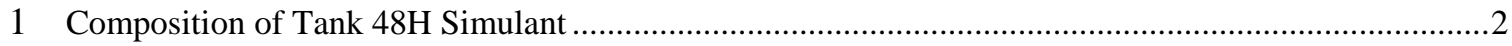

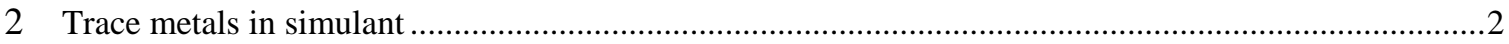

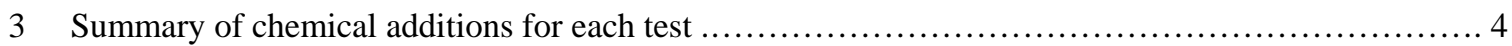

4 Total organic carbon (TOC) and total suspended solids (TSS) concentrations in

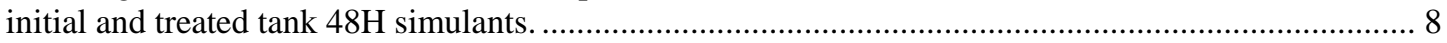

5 Metal concentrations in unwashed simulant and treated slurries..................................10

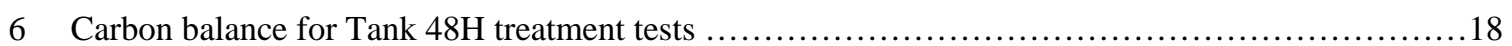





\begin{abstract}
High-level-waste Tank 48H at the Savannah River Site (SRS) contains about 50,000 lb of tetraphenylborate (TPB), which must be destroyed to return the tank to active service. Laboratory-scale tests were conducted to evaluate the use of Fenton's Reagent (hydrogen peroxide and a metal catalyst) to treat simulants of the Tank $48 \mathrm{H}$ waste. Samples of the treated slurry and the off-gas were analyzed to determine the reaction products. Process parameters developed earlier by AEA Technology were used for these tests; namely (for $500 \mathrm{~mL}$ of waste simulant), reduce $\mathrm{pH}$ to 7.5 with nitric acid, heat to boiling, add hydrogen peroxide at $1 \mathrm{~mL} / \mathrm{min}$ for $1 \mathrm{~h}$, reduce $\mathrm{pH}$ to 3.5, and add the remaining peroxide at $2 \mathrm{~mL} / \mathrm{min}$. These parameters were developed to minimize the formation of tarry materials during the early part of the reaction and to minimize the concentration of total organic carbon in the final treated slurry. The treated samples contained low concentrations of total organic carbon (TOC) and no detectable TPB. Tests using a mixture of iron and copper salts as the Fenton's catalyst had a lower TOC concentration in the final treated slurry than did tests that used a copper-only catalyst. TPB is known to hydrolyze to benzene, particularly at high temperature and low $\mathrm{pH}$, and copper is known to increase the rate of hydrolysis. Significant amounts of benzene were present in the off-gas from the tests, especially during the early portion of the treatment, indicating that the hydrolysis reaction was occurring in parallel with the oxidation of the TPB by Fenton's reagent. For the reaction conditions used in these tests, approximately equal fractions of the TPB were converted to benzene and carbon dioxide. Minimizing the formation of benzene is important to SRS personnel; however, this consideration was not addressed in the AEA-recommended parameters, since they did not analyze for benzene in the off-gas. Smaller amounts of carbon monoxide and other organics were also produced. One test used a simulant with much lower concentrations of salts, representing washed sludge, and this test produced much smaller amounts of benzene. The nitrite ions in the simulant were oxidized to nitrate, which would increase the amount of peroxide required to oxidize all of the organic carbon. Oxygen is the primary constituent of the off-gas produced from treatment of the samples.
\end{abstract}





\section{INTRODUCTION}

Tank 48H, a high-level-waste tank at the Savannah River Site (SRS), contains approximately 250,000 gal of salt waste and 50,000 lb of potassium tetraphenylborate (KTPB). The tetraphenylborate (TPB) was added to Tank $48 \mathrm{H}$, as the sodium salt, during the demonstration and startup of the in-tank precipitation process to remove radioactive cesium from the supernate in the tank. The KTPB slowly decomposes to form benzene, which is flammable and toxic.

In FY 2002, SRS conducted a study to identify options, evaluate alternatives, and recommend a selected alternative for processing Tank $48 \mathrm{H}$ contents to a waste form that can be processed or stored in existing or planned facilities. The use of Fenton's reagent (hydrogen peroxide and a metal ion catalyst) was chosen as a potential process to treat the tank waste. Fenton's reagent is an oxidation process developed by H. J. H. Fenton in $1894 .{ }^{1}$ Although the process is over 100 years old, it is quickly emerging as a state-of-the-art remedial technique for the twenty-first century. ${ }^{2}$ Fenton's reagent is a very strong oxidant that has been used in a variety of applications for organic destruction. The Fenton's Reagent process involves the reaction of hydrogen peroxide with the catalyst (usually iron, but other transition metals will also work) to form hydroxyl free radicals $(\mathrm{OH} \bullet)$. With an oxidation potential of $2.8 \mathrm{~V}$, the hydroxyl free radical is a very powerful oxidant, second only to fluorine, and will react with a wide range of organic molecules. Fenton's reagent has been used to treat a variety of industrial wastes containing a range of toxic organic compounds (e.g., phenols, formaldehyde, and complex wastes derived from dyestuffs, pesticides, wood preservatives, plastics additives, and rubber chemicals). The process has also been applied to wastewaters, sludges, and contaminated soils. ${ }^{2}$ Work in 2002 demonstrated that Fenton's Reagent could be used to destroy ion-exchange resin present in transuranic waste from two underground storage tanks (the T1 and T2 tanks) at Oak Ridge National Laboratory (ORNL). ${ }^{3}$

Complementary development work is being conducted at AEA Technology (Oxfordshire, United Kingdom), the Savannah River Technology Center (SRTC), and ORNL to develop the Fenton's reagent process for treating the Tank $48 \mathrm{H}$ waste. SRTC is developing an in-tank process and coordinating all of the work. AEA Technology is developing an out-of-tank process, in which a lower $\mathrm{pH}$ and higher temperature can be used, and ORNL is running larger-scale tests of the outof-tank process to gather more analytical data on the liquid and gaseous effluents from the process. The main objective of the research is to develop processing conditions for the safe destruction of the organic present in Tank $48 \mathrm{H}$ and allow the tank to be returned to routine highlevel-waste service. The processing conditions are being developed using nonradioactive simulants. The process viability will later be demonstrated through pilot-scale and actual waste testing. 


\section{MATERIALS AND METHODS}

The chemical composition of the unwashed Tank 48H simulant used in most of the testing, which is based on waste characterization by SRS, is summarized in Table 1. The predicted composition of washed slurry, in which dilute $\mathrm{NaOH}$ would be used to remove most of the salts, is also shown in Table 1. The washed simulant was used in one test. Both simulants were prepared from reagent-grade chemicals. The sodium tetraphenylborate (NaTPB) precipitates as KTPB in the simulant to form a fluffy white solid. Just prior to starting a test, the trace metals shown in Table 2 (as stock solutions in dilute $\mathrm{HNO}_{3}$ or $\mathrm{NaOH}$ ) were added to the simulant. Diphenyl mercury (150 mg/L) and $500 \mathrm{mg} / \mathrm{L}$ of monosodium titanate (MST) were also added as solids, and sludge simulant (500 mg/L of solids), obtained from SRS, was added as a slurry in water.(Note SRS later reported that the sludge and MST concentration should have been $0.2 \mathrm{wt} \%$, rather than $500 \mathrm{mg} / \mathrm{L}$ to correctly represent the Tank $48 \mathrm{H}$ waste.) AEA Technology originally recommended using $200 \mathrm{mg} / \mathrm{L}$ of copper and $200 \mathrm{mg} / \mathrm{L}$ of iron for the Fenton's catalyst, a procedure that was used for tests 1-3. Later work at AEA suggested that using only $200 \mathrm{mg} / \mathrm{L}$ copper produced better organic removal. Therefore, this catalyst was used for tests 4-6. The catalyst was added as the nitrate salt dissolved in $5 \mathrm{~mL}$ of $5 \mathrm{M} \mathrm{HNO}_{3}$. Copper, palladium, and other metals are also known to catalyze the hydrolysis of TPB to benzene, particularly at low $\mathrm{pH}$ and high temperatures. Determining the relative amounts of benzene (from hydrolysis) and carbon dioxide (from the Fenton reaction) that were produced was an important part of these tests.

Table 1. Composition of Tank $48 \mathrm{H}$ Simulant

\begin{tabular}{|c|c|c|}
\hline \multirow[b]{2}{*}{ Component } & \multicolumn{2}{|c|}{ Concentration $(M)$} \\
\hline & Unwashed $^{\mathrm{a}}$ & Washed $^{\mathrm{a}}$ \\
\hline NaTPB & 0.0728 & 0.0728 \\
\hline $\mathrm{NaOH}$ & 1.8425 & 0.0405 \\
\hline $\mathrm{NaNO}_{2}$ & 0.4709 & 0.0104 \\
\hline $\mathrm{NaNO}_{3}$ & 0.2753 & 0.0000 \\
\hline $\mathrm{Na}_{2} \mathrm{CO}_{3}$ & 0.1295 & 0.0028 \\
\hline $\mathrm{NaAlO}_{2}$ & 0.1118 & 0.0025 \\
\hline $\mathrm{Na}_{2} \mathrm{SO}_{4}$ & 0.0071 & 0.0002 \\
\hline $\mathrm{Na}_{3} \mathrm{PO}_{4}$ & 0.0077 & 0.0002 \\
\hline $\mathrm{NaCl}$ & 0.0088 & 0.0002 \\
\hline $\mathrm{NaF}$ & 0.0059 & 0.0001 \\
\hline $\mathrm{KNO}_{3}$ & 0.0779 & 0.0729 \\
\hline KTPB, wt \% & $2.32 \%$ & $2.59 \%$ \\
\hline
\end{tabular}

${ }^{\mathrm{a}}$ The densities of the unwashed and washed simulants are 1.125 and $1.010 \mathrm{~g} / \mathrm{cm}^{3}$, respectively.
Table 2. Trace metals in simulant

\begin{tabular}{|c|c|}
\hline Compound & Conc. (mg/mL) \\
\hline $\mathrm{Cu}\left(\mathrm{SO}_{4}\right) \cdot 5 \mathrm{H}_{2} \mathrm{O}$ & 3.7 \\
\hline $\mathrm{Na}_{2} \mathrm{MoO}_{4} \cdot 2 \mathrm{H}_{2} \mathrm{O}$ & 12 \\
\hline $\mathrm{Na}_{2} \mathrm{CrO}_{4}$ & 60 \\
\hline $\mathrm{Na}_{2} \mathrm{SiO}_{3} \cdot 9 \mathrm{H}_{2} \mathrm{O}$ & 16 \\
\hline $\mathrm{Na}_{2} \mathrm{SeO}_{4}$ & 1.0 \\
\hline $\mathrm{As}_{2} \mathrm{O}_{3}$ & 0.04 \\
\hline $\mathrm{Zn}\left(\mathrm{NO}_{3}\right)_{2} \cdot 6 \mathrm{H}_{2} \mathrm{O}$ & 8.8 \\
\hline $\mathrm{Pb}\left(\mathrm{NO}_{3}\right)_{2}$ & 1.2 \\
\hline $\mathrm{Fe}\left(\mathrm{NO}_{3}\right)_{3} \cdot 9 \mathrm{H}_{2} \mathrm{O}$ & 2.6 \\
\hline $\mathrm{SnCl}_{2} \cdot 2 \mathrm{H}_{2} \mathrm{O}$ & 2.1 \\
\hline $\mathrm{Hg}\left(\mathrm{NO}_{3}\right)_{2} \cdot \mathrm{H}_{2} \mathrm{O}$ & 2.2 \\
\hline $\mathrm{Ca}\left(\mathrm{NO}_{3}\right)_{2} \cdot 4 \mathrm{H}_{2} \mathrm{O}$ & 12.2 \\
\hline $\mathrm{Sr}\left(\mathrm{NO}_{3}\right)_{2}$ & 0.1 \\
\hline $\mathrm{La}\left(\mathrm{NO}_{3}\right)_{3} \cdot 6 \mathrm{H}_{2} \mathrm{O}$ & 0.05 \\
\hline $\mathrm{Co}\left(\mathrm{NO}_{3}\right)_{2} \cdot 6 \mathrm{H}_{2} \mathrm{O}$ & 0.04 \\
\hline $\mathrm{Cd}\left(\mathrm{NO}_{3}\right)_{2} \cdot 4 \mathrm{H}_{2} \mathrm{O}$ & 0.4 \\
\hline $\mathrm{Ce}\left(\mathrm{NO}_{3}\right)_{3} \cdot 6 \mathrm{H}_{2} \mathrm{O}$ & 0.3 \\
\hline $\mathrm{Rh}\left(\mathrm{NO}_{3}\right)_{3}$ & 1.4 \\
\hline $\mathrm{Pd}\left(\mathrm{NO}_{3}\right)_{2} \bullet x \mathrm{H}_{2} \mathrm{O}$ & 13 \\
\hline $\mathrm{AgNO}_{3}$ & 6.8 \\
\hline $\mathrm{RuCl}_{3} \bullet x \mathrm{H}_{2} \mathrm{O}$ & 5.4 \\
\hline
\end{tabular}

The tests were conducted in a 2-L flask on a hot plate/stirrer, using $0.5 \mathrm{~L}$ of Tank 48 simulant (see Fig. 1). A piece of $1 / 4$-in. stainless steel tubing extended from the top rubber stopper down into the slurry, and liquid samples were collected through this tube using $1 / 16$-in.-OD plastic 
tubing and a suction bulb. A water-cooled condenser was used to remove moisture from the offgas. Condensate was returned to the reaction flask through the tubing connected to the flask tubulation. The trace metals plus diphenyl mercury, sludge simulant, and MST were added just before conducting a test. The first test, plus tests 4 through 6 , used the procedure recommended by AEA Technology: reduce $\mathrm{pH}$ to 7.5 with $5 \mathrm{M} \mathrm{HNO}_{3}$, heat to boiling, add $\mathrm{H}_{2} \mathrm{O}_{2}$ at $1 \mathrm{~mL} / \mathrm{min}$ for $1 \mathrm{~h}$, reduce $\mathrm{pH}$ to 3.5, and add the remaining $\mathrm{H}_{2} \mathrm{O}_{2}$ at $2 \mathrm{~mL} / \mathrm{min}$. Test 2 was run at $1 \mathrm{pH}$ unit higher (8.5 and 4.5), while test 3 was run at $1 \mathrm{pH}$ unit lower (6.5 and 2.5). The $\mathrm{HNO}_{3}$ was pumped into the simulant at about $2 \mathrm{~mL} / \mathrm{min}$, taking about 1 hour to neutralize the slurry, except for test 6 (washed stimulant), which used much less acid. Heating the slurry to the boiling point took about 30-45 minutes, and then the peroxide addition was started, which lasted about $3.5 \mathrm{~h}$. The lines for adding peroxide and acid ended above the level of the slurry for tests 1-3 but were extended down into the slurry for tests 4-6 to provide faster dispersal into the slurry.

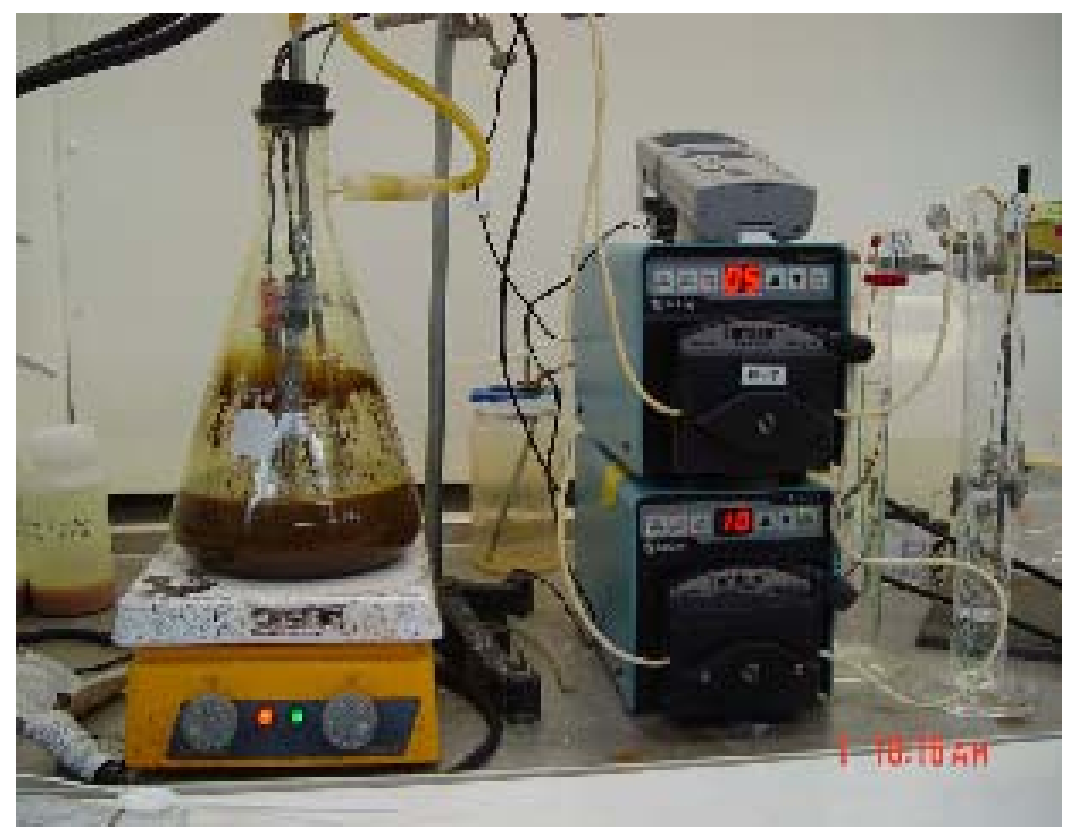

Fig. 1. Test setup for treating Tank 48 simulants. Acid and peroxide are added using peristaltic pumps and 1/32-in.-I.D. tubing. The off-gas condenser above the flask is not shown.

The off-gas was collected in Tedlar bags, and the volume was measured using a large gas syringe. The gas samples were analyzed for $\mathrm{O}_{2}$, CO, and NO using a Model 400 emissions monitoring system (ENERAC, Inc., Westbury, N.Y.). Selected samples were analyzed for $\mathrm{O}_{2}, \mathrm{~N}_{2}, \mathrm{CO}_{2}$, and benzene via gas chromatography (GC) and analyzed for organics by GC-mass spectroscopy (GCMS). One composite sample from all of the off-gas and a sample from the final bag of gas were collected for tests 1-3 for analysis by GC-MS. For tests 4-6, a sample of the headspace within the reaction flask was collected just before peroxide addition was started. Composite samples of off-gas were then collected each hour and the final bag of gas was sampled for analysis by GC and GC-MS. The total volume of empty space in the off-gas system, including the reaction flask, condenser, water trap, and tubing, is about $1.9 \mathrm{~L}$. Therefore, the final gas samples would include some residual from gas generated earlier in the reaction. In order to eliminate the residual gas, the flask headspace and off-gas system were purged with argon prior to adding the last $20 \mathrm{~mL}$ of 
peroxide for tests 5 and 6 , which would remove any previously generated benzene from the offgas system. The last bag of gas for tests 5 and 6 , which was collected after the peroxide addition was restarted, contained only the benzene that was generated during the last part of the test. The GC analysis includes the argon concentration, so that the dilution of the off-gas generated by the reaction can be calculated.

Samples of the final treated slurries were analyzed for semivolatiles by GC-MS and for TPB, triphenylborane, phenylboronic acid, and phenol by high-pressure liquid chromatography (HPLC). Samples were also digested and analyzed for metals by inductively-coupled plasmaemission spectroscopy (ICP-ES). Small samples of the slurry were collected about once each hour during treatment for analysis of total organic carbon (TOC). The suspended solid and liquid phases of these samples were separated and analyzed individually to improve the detection limit for the slurry.

\section{RESULTS AND DISCUSSION}

The amount of acid, base, and peroxide used for each test is summarized in Table 3 . The $350 \mathrm{~mL}$ of $50 \mathrm{wt} \%$ peroxide added is 2.5 times the stoichiometric amount needed to convert all of the TPB in $500 \mathrm{~mL}$ of simulant to carbon dioxide and water. The acid volumes listed include the $5 \mathrm{~mL}$ of acid used to add the Fenton's catalyst. Sodium hydroxide was not needed for $\mathrm{pH}$ control, except for test 6 . The $\mathrm{pH}$ of the washed simulant used for test 6 was difficult to control, due to a continued slow drift of the $\mathrm{pH}$ after acid or base addition was stopped. The sodium hydroxide was needed to correct an overshoot of the planned initial $\mathrm{pH}$ adjustment to 7.5.

Table 3. Summary of chemical additions for each test

\begin{tabular}{cccc}
\hline Test \# & $5 \mathrm{M} \mathrm{HNO}_{3}(\mathrm{~mL})$ & $1 \mathrm{M} \mathrm{NaOH}(\mathrm{mL})$ & $50 \% \mathrm{H}_{2} \mathrm{O}_{2}(\mathrm{~mL})$ \\
\hline 1 & 260 & 0 & 350 \\
2 & 252 & 0 & 350 \\
3 & 261 & 0 & 350 \\
4 & 258 & 0 & 350 \\
5 & 257 & 0 & 350 \\
6 & 14.6 & 14 & 350 \\
\hline
\end{tabular}

Figure 2 shows a series of photographs of the reaction flask during the treatment for test 5 . The dark-colored film on the walls of the flask is visible in Figs. 2(b) and 2(c), but has almost disappeared in Fig. 2(d). A layer of darker-colored foam is present on top of the slurry in Fig. 2(d). Figure 2(e) shows the yellow deposits that formed on the inside of the condenser during each of the tests. Figure 2(f) shows the high concentration of $\mathrm{NO}_{x}$ gas that was generated just after the $\mathrm{pH}$ was reduced to 3.5. The $\mathrm{NO}_{x}$ concentrations were much lower during most of the treatment and were not detectable in the last few gas samples.

Figure 3 shows the treatment sequence for test 6 , which used the washed stimulant. More foam ( $\sim 2$ in.) was present on top of the slurry during this test than for all of the others, probably due to the lower salt concentration. The washed stimulant has a much lower concentration of aluminum than the unwashed stimulant, which was used for the other tests. Therefore, the suspended solids concentration is lower. The treated slurry is almost transparent, as a result of the low concentration of suspended solids. 


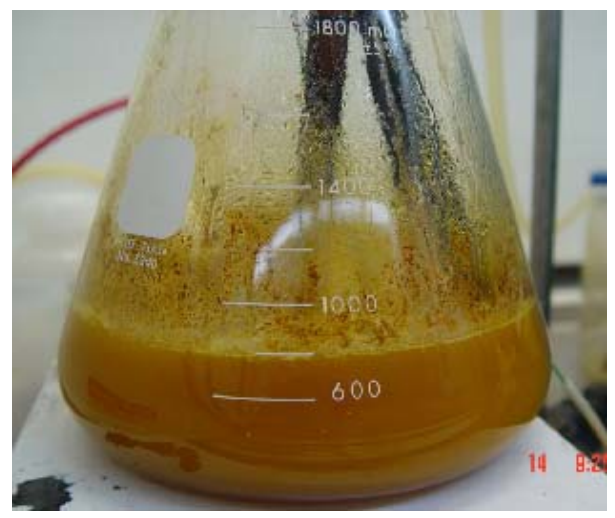

(a). Acid added to $\mathrm{pH}=7.5$, heated.

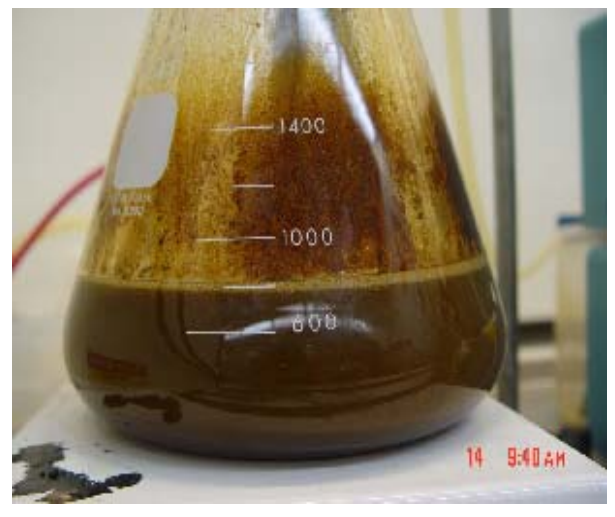

(b). Treated $1 \mathrm{~h}, \mathrm{pH}=7.5$.

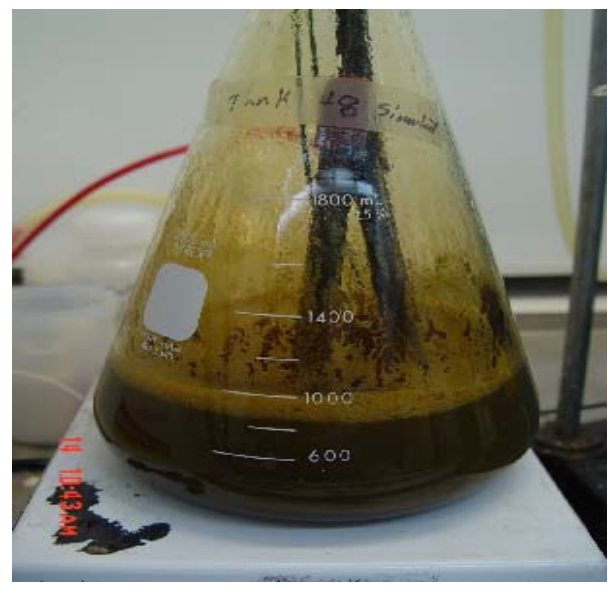

(c). Treated $2 \mathrm{~h}, \mathrm{pH}=3.5$.

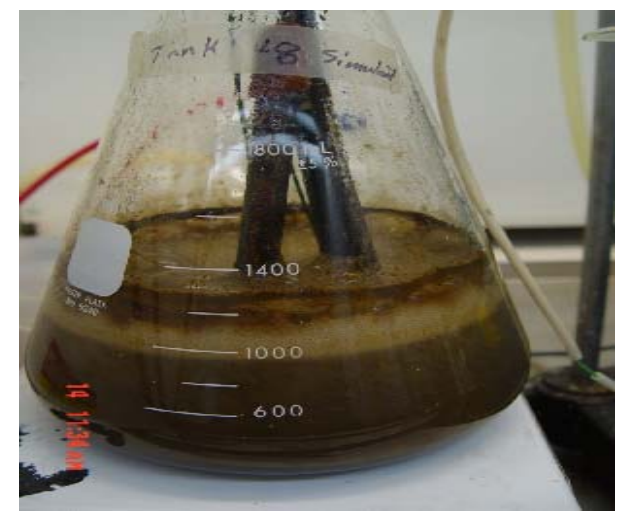

(d). Just before completion of treatment.

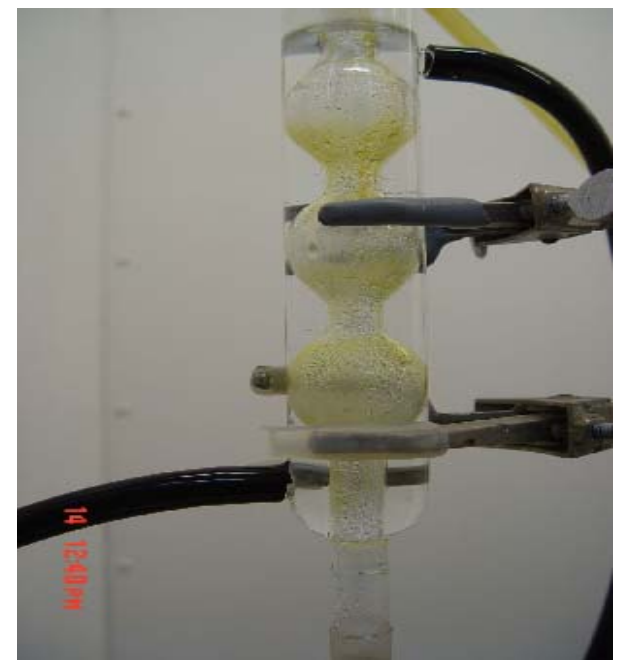

(e). Condenser with yellow deposits.

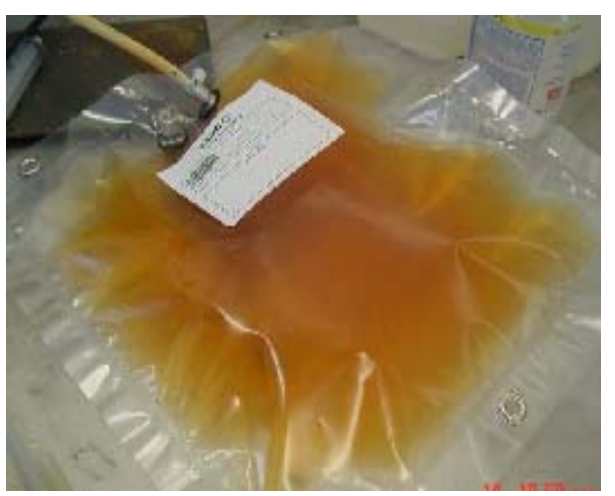

(f). $\mathrm{NO}_{x}$ in off-gas, just after reducing $\mathrm{pH}$ to 3.5 .

Fig. 2. Treatment sequence for test 5 , plus views of condenser and off-gas. 


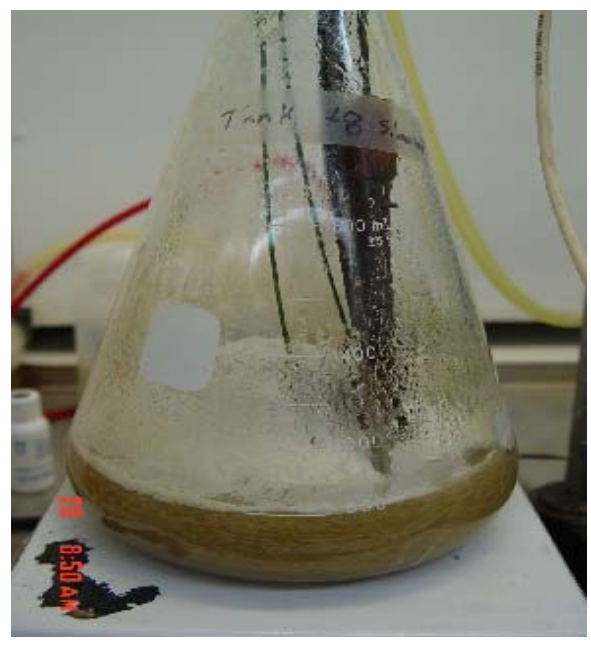

(a). Acid added to $\mathrm{pH}=3.5$, heated, peroxide started.

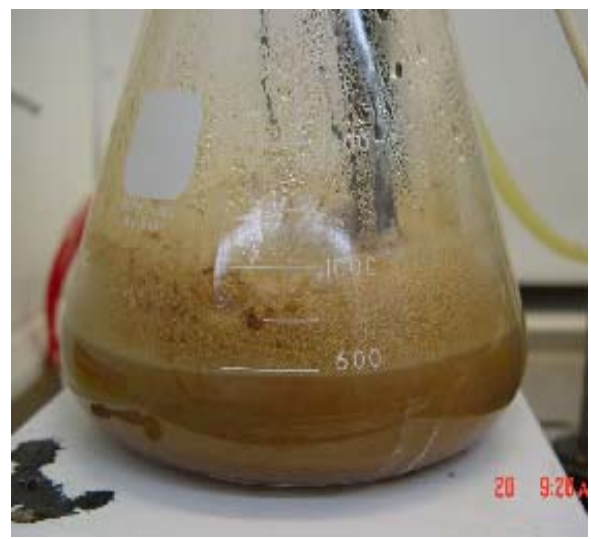

(b). Treated for $1 \mathrm{~h}, \mathrm{pH}=7.5$.

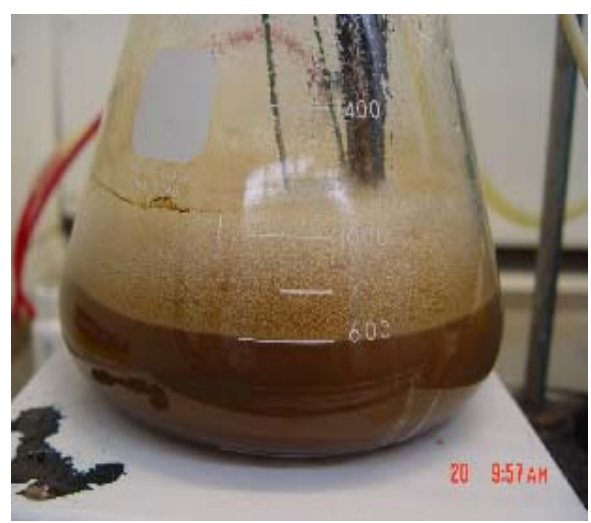

(c). Treated for $2 \mathrm{~h}, \mathrm{pH}=3.5$

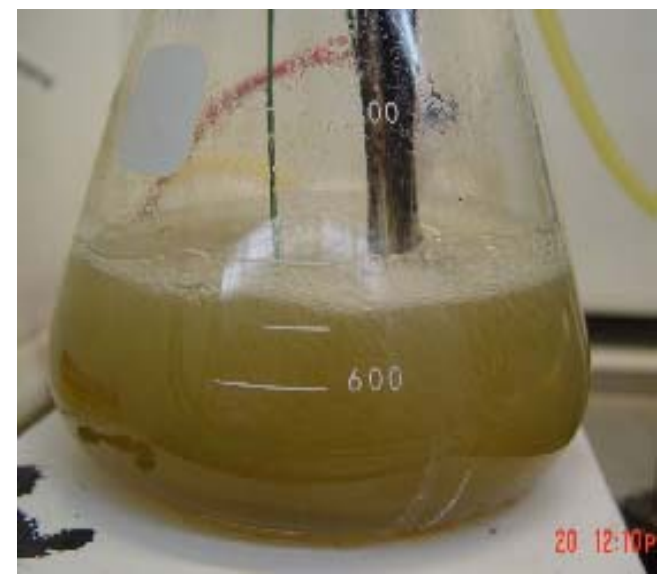

(d). Treated for $3 \mathrm{~h}, \mathrm{pH}=3.5$.

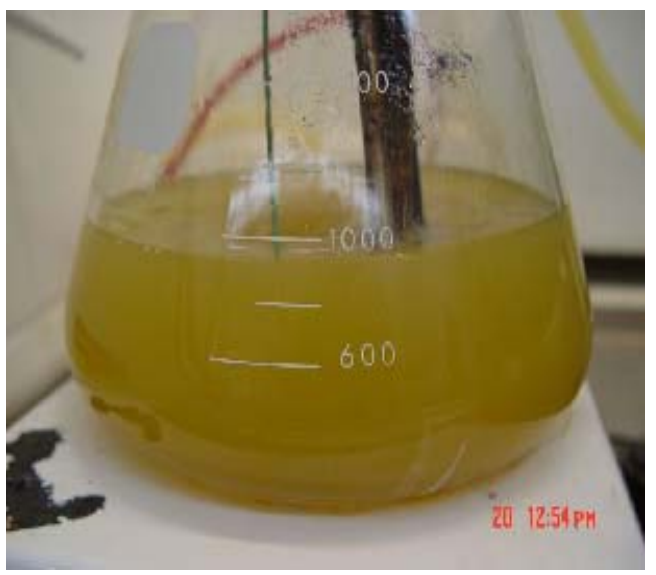

(e). Treatment complete.

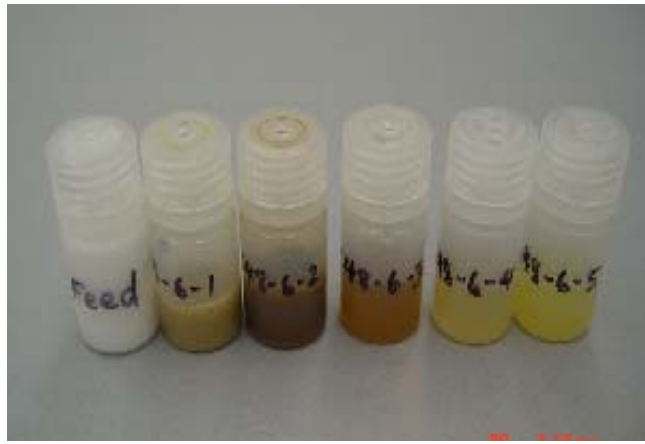

(f). Sequence of samples for analysis of total organic carbon. Feed = washed stimulant, no trace metals yet added. Remaining samples correspond to photos above.

Fig. 3. Treatment sequence for test 6. 
Tests 1 and 2 used a long condenser with a small ( 1/16-in.-ID) glass tube for the gas flow. The line plugged several times, causing gas to leak around penetrations in the rubber stopper at the top of the reaction flask and also forcing slurry up out of the sample tube. The slurry was pumped back into the reaction flask, but an unknown amount of gas was lost. For the remaining tests, a shorter condenser with a larger (1/4-in.-ID) opening was used. For test 3, a mass flowmeter was connected to the off-gas line, downstream of the condenser, to give a real-time measurement of the off-gas flow rate. The meter worked initially but then started plugging as either water vapor or organics coated the inlet filter. The mass flow meter was removed, but some gas was lost prior to removing the meter. No off-gas line plugging problems occurred during tests 4-6. During test 2 , the hot plate was mistakenly turned on before the acid addition was started. The hot plate was turned off when the temperature had reached $68^{\circ} \mathrm{C}$, but the temperature continued to climb as acid was added, reaching $98^{\circ} \mathrm{C}$ before cooling back down to $70^{\circ} \mathrm{C}$ by the time all of the acid had been added. In test 5 , high temperatures were also experienced for a longer period of time, due to the failure of the $\mathrm{pH}$ probe after the $\mathrm{pH}$ had been adjusted to 7.5 and the slurry had been heated to the boiling point. The hot plate was turned off while the $\mathrm{pH}$ probe was replaced, but the slurry remained near the boiling point for an extra $30 \mathrm{~min}$ before addition of peroxide was started. During this time period, the color of the slurry darkened, presumably due to the formation of tarry compounds from breakdown of the TPB. No other significant problems were encountered during the tests. Foam production was very low for tests $1-5$, which used the unwashed simulant, and moderate for test 6 , which used washed simulant.

\subsection{ANALYTICAL RESULTS FOR LIQUID SAMPLES}

The feed slurries, intermediate samples, and the final treated slurries were analyzed for TOC. When analyzed as a slurry, many of the samples were below the detection limit of $0.1 \%$. Therefore, the samples were filtered and the liquid and solids portions were analyzed separately. The detection limit for the liquid samples is $10 \mathrm{mg} / \mathrm{L}$, and the detection limit for the solids is still $0.1 \%$; however, a larger amount of solids can be analyzed, which gives a better detection limit for the original slurry. The total suspended solids (TSS) concentration in the samples was measured and used to calculate the TOC concentration in the treated slurries from the solid and liquid TOC results. The TOC and TSS results for the final treated slurry from each of the six tests are listed in Table 4, and the calculated slurry TOC concentrations for all of the samples are shown in Fig. 4. The TOC concentrations in the untreated stimulant slurries are significantly lower than the expected concentration of $2.1 \%$ TOC for $0.0728 M$ TPB. The solids portion of each sample is collected on a filter and then dried at $100^{\circ} \mathrm{C}$ for several hours before being analyzed. It is likely that some hydrolysis of the TPB occurs during drying, releasing benzene, which then evaporates. The feed samples and possibly the first few treated samples from each test would be affected by the hydrolysis, giving artificially low TOC results. Analysis of the final treated samples for TPB, described below, shows that the TPB has been completely destroyed; therefore, these samples should not be affected by hydrolysis during drying. The percentage of TOC removal for the treated samples from each test is calculated using the measured TOC concentrations in the feed simulants. Using the TOC concentration predicted from the concentration of TPB (2.1\% TOC) added to the simulants would give even higher values for percentage of TOC removals, especially for test 6 . 
Table 4. Total organic carbon (TOC) and total suspended solids (TSS) concentrations in initial and treated Tank $48 \mathrm{H}$ simulants

\begin{tabular}{|c|c|c|c|c|c|}
\hline \multirow{2}{*}{$\begin{array}{c}\text { Sample } \\
\text { description }\end{array}$} & \multicolumn{3}{|c|}{ TOC concentrations } & \multirow{2}{*}{$\begin{array}{c}\text { \% TOC } \\
\text { Removed }\end{array}$} & \multirow[b]{2}{*}{ TSS (g/mL) } \\
\hline & Liquid (mg/L) & Solid (\%) & Slurry $(\%)^{\mathrm{a}}$ & & \\
\hline $\begin{array}{l}\text { Unwashed } \\
\text { Simulant }\end{array}$ & 1460 & 25 & 0.92 & & 30.8 \\
\hline Test 1 & $<10$ & $<0.1$ & $<0.001$ & $>99.9$ & 4.81 \\
\hline Test 2 & 19.4 & 0.23 & 0.003 & 99.7 & 5.46 \\
\hline Test 3 & 105 & 0.91 & 0.015 & 98.4 & 4.55 \\
\hline Test 4 & 21.6 & 0.56 & 0.004 & 99.5 & 3.59 \\
\hline Test 5 & 24.4 & 0.50 & 0.005 & 99.4 & 4.64 \\
\hline $\begin{array}{l}\text { Washed } \\
\text { Simulant }\end{array}$ & 44.5 & 14.3 & 0.38 & & 26.6 \\
\hline Test 6 & 23.6 & 0.51 & 0.003 & 99.3 & 0.72 \\
\hline
\end{tabular}

${ }^{\mathrm{a} C a l c u l a t e d ~ f r o m ~ m e a s u r e d ~ l i q u i d ~ a n d ~ s o l i d ~ T O C ~ r e s u l t s ~ a n d ~ T S S ~ r e s u l t s . ~}$

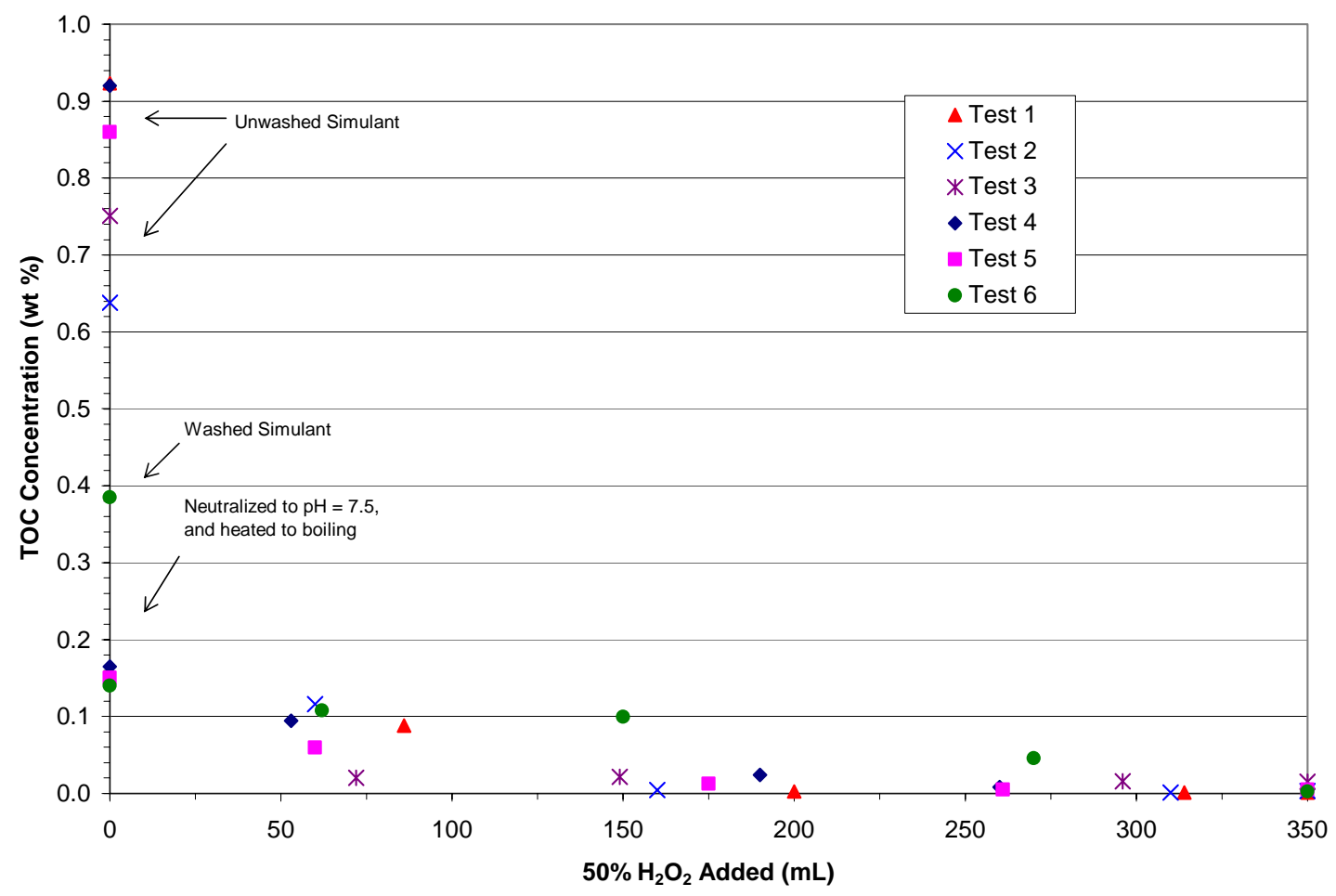

Fig. 4. Total organic carbon concentrations of slurries during treatment. 
The TOC concentration in all of the treated slurries was quite low. For tests 1-3, which used iron and copper as the Fenton's catalyst, the results show better organic carbon destruction for test 1 , which used the $\mathrm{pH}$ regime recommended by AEA Technology, than for test 2 at higher or test 3 at lower pH's. Tests 4 and 5, which used a copper-only catalyst and the same $\mathrm{pH}$ regime as test 1 , also show poorer TOC destruction than for test 1 . Test 6 , which used washed stimulant and the copper only catalyst, showed TOC results similar to those for the tests using washed simulant.

For each of the tests, there was a dark-colored coating that formed on the inside wall of the reaction flask, above the layer of the liquid, and a yellow-colored coating on the inside of the condenser and off-gas tubing. After test 3 , the flask and condenser were each washed with $100 \mathrm{~mL}$ of methylene chloride, which dissolved the coatings. The total amounts of residue recovered were $0.049 \mathrm{~g}$ from the condenser and off-gas line and $0.109 \mathrm{~g}$ from the flask. Analysis of the dried residue showed an organic carbon concentration of $15.7 \mathrm{wt} \%$ for the flask and $54.2 \mathrm{wt} \%$ for the condenser. For tests 4-6, less dark coating initially formed on the inside of the flask, and this coating had disappeared by the end of the reaction; however, the yellow coating inside the condenser and off-gas line was still present. Methylene chloride was used to remove the residue after each test. The amounts of residue recovered from the condenser and off-gas line were $0.14 \mathrm{~g}$ for test $4,0.048 \mathrm{~g}$ for test 5 , and $0.14 \mathrm{~g}$ for test 6 . Analysis of the methlyene chloride solutions for semivolatiles showed that biphenyl (160-550 mg/L) was the only identifiable constituent, while several other unknown compounds were also present at much lower concentrations. The biphenyl accounts for up to $50 \%$ of the TOC concentration measured in the methylene chloride washes.

The final treated slurries from each test were also analyzed for semi-volatiles. Several identifiable compounds were present at low concentrations $(0.1-1.0 \mathrm{mg} / \mathrm{L})$, including phenol, biphenyl, $N$-nitrosodiphenylamine, 2-nitrophenol, 4-hydroxy-4-methyl-2-pentanone, and $\mathrm{N}, \mathrm{N}$-diphenylbenzenamine. A number of unknown peaks were also present at concentrations estimated at up to $1 \mathrm{mg} / \mathrm{L}$. Concentrations of up to $36 \mathrm{mg} / \mathrm{L}$ were measured for bis(2-ethylhexyl) phthalate; however, because this compound is a common plasticizer that is unlikely to be formed during the reaction, it is probably a contaminant. Two of the samples were analyzed for benzene, but the concentration was less than the detection limit of $0.001 \mathrm{mg} / \mathrm{L}$. A large amount of benzene was formed during the treatment of the simulant samples (see gas analysis results in Sect. 3.2), but it apparently all evaporated from the boiling slurry.

The treated slurries were also analyzed for TPB and its breakdown products using HPLC. These compounds were not detected in any of the samples. The detection limits are $30 \mathrm{mg} / \mathrm{L}$ for TPB, $3 \mathrm{mg} / \mathrm{L}$ for triphenyl borane, $5 \mathrm{mg} / \mathrm{L}$ for phenylboronic acid, and $10 \mathrm{mg} / \mathrm{L}$ for phenol.

Analysis of the feed and final treated slurry from tests 3 and 6 for anions, using liquid chromatography, showed that all of the nitrite was oxidized to nitrate during the treatment. The peroxide oxidized the nitrite as well as the organics, which would increase the amount of peroxide required by about $20 \%$ for complete destruction of the organics in the unwashed slurry.

The concentration of metals in the unwashed simulant and the final treated slurries is shown in Table 5. The simulant slurry was sampled before the trace metals (see Table 2) were added. The concentrations of $\mathrm{Al}, \mathrm{B}, \mathrm{K}$, and $\mathrm{Na}$ in the treated slurries were reduced by over $50 \%$ from dilution with the acid and peroxide, compared with the concentration in the starting simulant. The washed stimulant used for test 6 contained much lower concentrations of $\mathrm{Al}$ and $\mathrm{Na}$ (see Table 1). The treated slurries have a final volume of about $1.1 \mathrm{~L}$ for tests $1-5$ and $0.9 \mathrm{~L}$ for test 6 , for a starting 
stimulant volume of $0.5 \mathrm{~L}$, which matches the change measured in the metal concentrations. The boron comes from the TPB and the titanium comes from the MST.

Table 5. Metal concentrations in unwashed simulant and treated slurries

\begin{tabular}{lccccccc}
\hline & \multicolumn{7}{c}{ Metal Concentrations $(\mathrm{mg} / \mathrm{L})$} \\
\cline { 2 - 8 } Analyte & Simulant & Test 1 & Test 2 & Test 3 & Test 4 & Test 5 & Test 6 \\
\hline $\mathrm{Al}$ & 2827 & 1417 & 1456 & 1305 & 1296 & 1301 & 44 \\
$\mathrm{~B}$ & 545 & 257 & 352 & 280 & 307 & 356 & 357 \\
$\mathrm{Cd}$ & $<0.5$ & 1.02 & 1.13 & 1.02 & 0.75 & 0.78 & 0.90 \\
$\mathrm{Cr}$ & $<0.5$ & 22 & 23 & 21 & 21 & 23 & 26 \\
$\mathrm{Cu}$ & $<0.5$ & 93 & 95 & 88 & 89 & 89 & 96 \\
$\mathrm{Fe}$ & $<5$ & 125 & 130 & 112 & 16 & 17 & 19 \\
$\mathrm{~K}$ & 3769 & 1958 & 2008 & 1760 & 1989 & 1923 & 1221 \\
$\mathrm{Mo}$ & $<0.5$ & 1.81 & 1.97 & 1.68 & 1.81 & 1.90 & 2.11 \\
$\mathrm{Na}$ & 71459 & 35302 & 36425 & 32842 & 33950 & 34212 & 2076 \\
$\mathrm{Ni}$ & $<0.5$ & 2.04 & 1.74 & 1.55 & 1.45 & 1.51 & 1.76 \\
$\mathrm{~Pb}$ & $<0.5$ & 1.37 & 1.37 & 1.24 & 1.16 & 1.31 & 1.40 \\
$\mathrm{Si}$ & $<5$ & 16 & 22 & 12 & 13 & 16 & 10 \\
$\mathrm{Ti}$ & $<0.5$ & 47 & 44 & 40 & 54 & 53 & 59 \\
$\mathrm{Zn}$ & $<5$ & 6.17 & 5.44 & 5.15 & 4.76 & 5.29 & 4.77 \\
\hline
\end{tabular}

A portion of each treated slurry was mixed and then poured into a 250 -mL graduated cylinder to determine settling characteristics. All of the treated slurries using the unwashed simulant (tests 15) showed similar settling rates (see Fig. 5). The solids in these slurries were very light and fluffy and settled slowly. The final volume of settled solids, after 6 days, ranged from 40 to $56 \mathrm{~mL}$ for the slurry from tests $1-5$. The treated slurry from test 6 (washed simulant) contained a low concentration of solids, including some aluminum, the copper catalyst, MST and sludge simulant. The larger particles settled to the bottom of the cylinder in less than 1 hour, and the slight hazy interface that was visible at a height of $17.3 \mathrm{~cm}$ after one hour had disappeared by the second hour. The volume of settled solids for the test 6 slurry was about $1 \mathrm{~mL}$.

Figures 6 and 7 show photographs of the treated slurries, after they had settled for 2 days. The supernate from test 3 , which was run at the lowest $\mathrm{pH}$, shows the least color, while the supernate from test 2, run at the highest $\mathrm{pH}$, shows the darkest color. The color of the supernate for test 6 , which used the washed stimulant, is darker than that for tests 1,4 , and 5 , which used the same $\mathrm{pH}$ and unwashed stimulant. Dichromate, which was added as part of the trace metals, is one likely source of the yellow color. The amount of dichromate in solution could depend on the $\mathrm{pH}$ and the amount of aluminum hydroxide, which can act as a sorbent for metals. The color of the settled sludge also varies between the different treated slurries, with the sludge from test 5 being the darkest. 


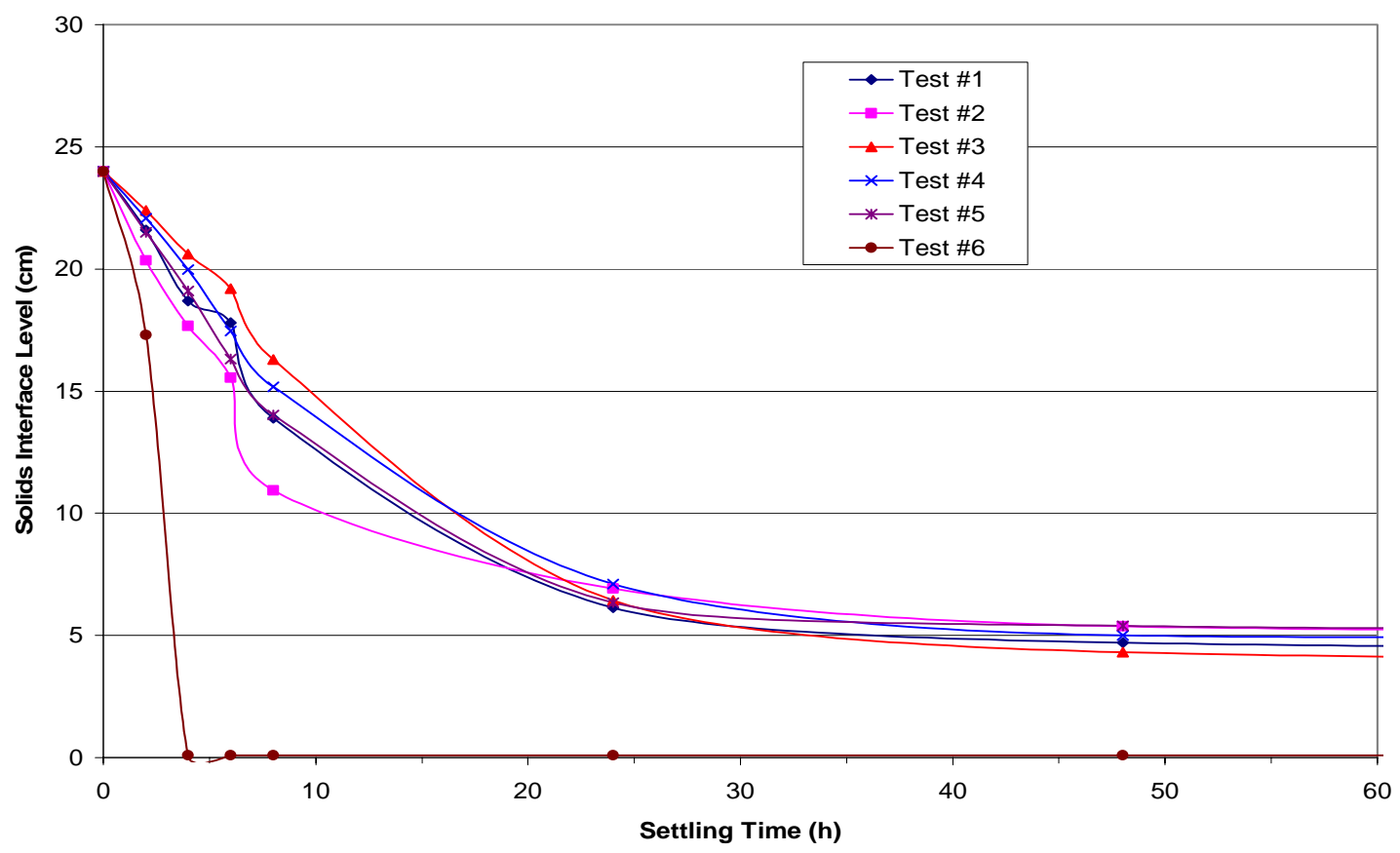

Fig. 5. Settling rates for treated simulant slurries.

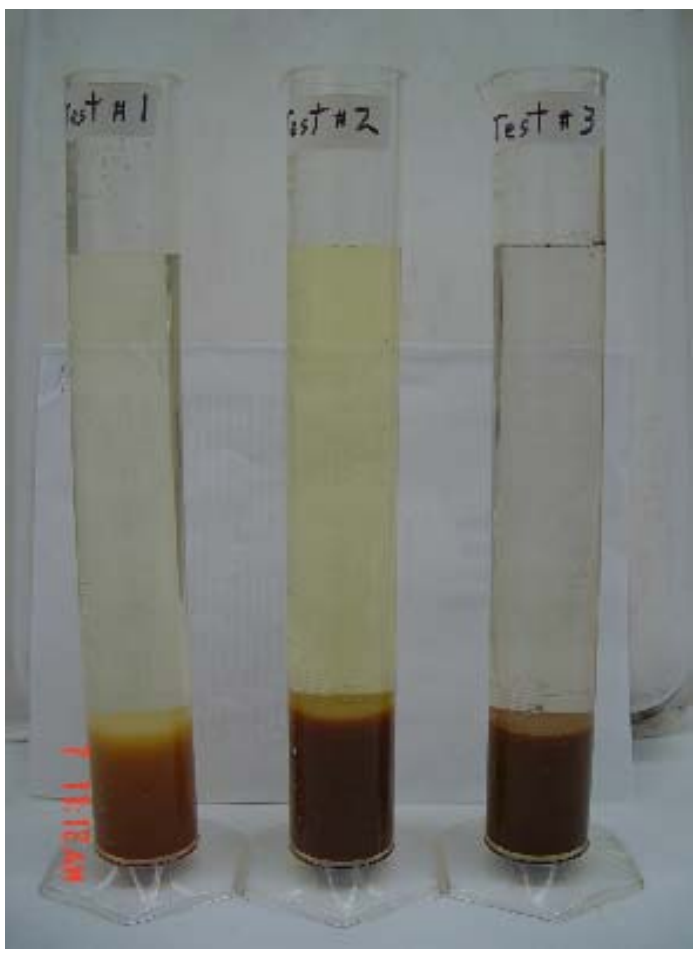

Fig. 6. Treated Tank $48 \mathrm{H}$ simulants from tests 1,2 , and 3 .

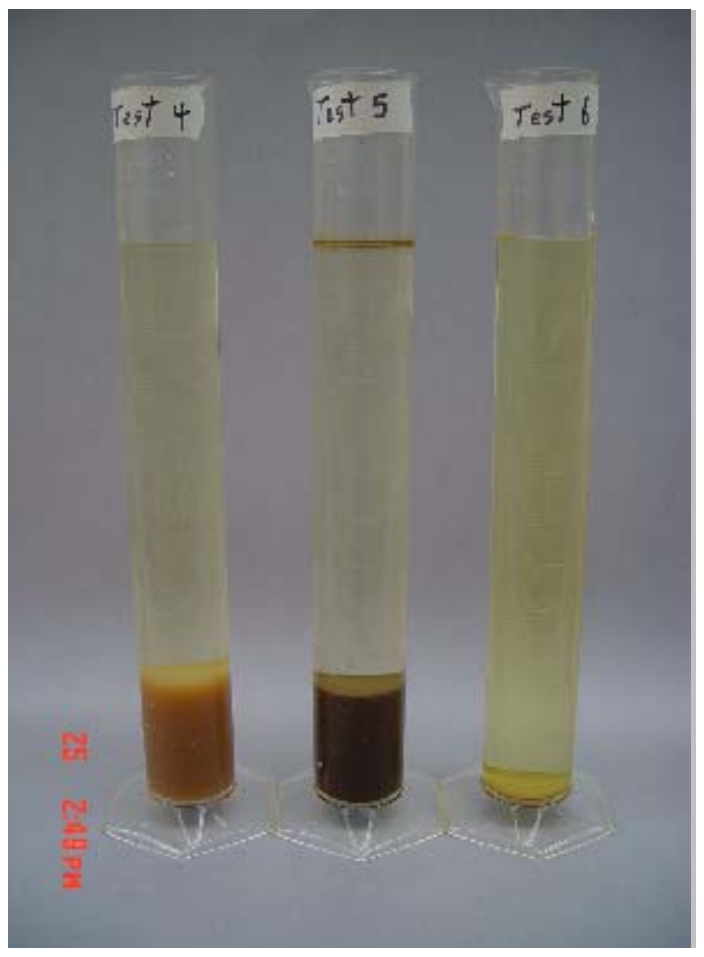

Fig. 7. Treated Tank $48 \mathrm{H}$ simulants from tests 4,5 , and 6 . 


\subsection{RESULTS FOR OFF-GAS SAMPLES}

For the first three tests, each bag of gas collected was analyzed using the emissions monitor, which measures $\mathrm{O}_{2}$, CO, and NO. Oxygen concentrations were $60-80 \%$ during the early portion of the treatment and then increased to near $100 \%$ at the end. The CO concentrations started high (2000-7000 ppm) and then dropped to $<100 \mathrm{ppm}$, while NO concentrations were highest (500$1300 \mathrm{ppm}$ ) just after the $\mathrm{pH}$ was reduced to the final value (3.5, 4.5, and 2.5, respectively, for tests 1,2 , and 3 ) and were $<20 \mathrm{ppm}$ for the last hour of treatment. The gas volume in each bag was also measured using a 1-L syringe, giving total volumes of $42-49 \mathrm{~L}$ for these tests. Some gas was lost during each of these tests due to plugging problems. As a result, the total gas volume measured was lower than that for the later tests. Figure 8 shows the off-gas results for test 3 .

One composite sample of all of the off-gas and a sample of the final bag of gas collected were analyzed for organics by GC-MS. The only exception to this procedure was test 1 , where one of the bags leaked before it was analyzed. For test 2 (higher $\mathrm{pH}$ ), the composite off-gas sample contained 11,000 ppmv of benzene and the last off-gas sample contained 1400 ppmv of benzene. No other organics were detected in the samples. For test 3 (lower $\mathrm{pH}$ ), the benzene results were much lower, 1668 ppmv in the composite sample and 341 ppmv in the final sample. Trace amounts $(<20 \mathrm{ppm})$ of acetone, acetaldehyde, phenol, and a nitrosubstituted alkane were also detected in both samples. The slurry for test 2 was exposed to high temperature for a longer period of time before peroxide addition was started, because the hot plate was mistakenly turned on early. High temperatures are known to increase the hydrolysis of TPB to benzene, which is consistent with the higher concentrations of benzene in the off-gas from test 2 , compared with those for test 3 .

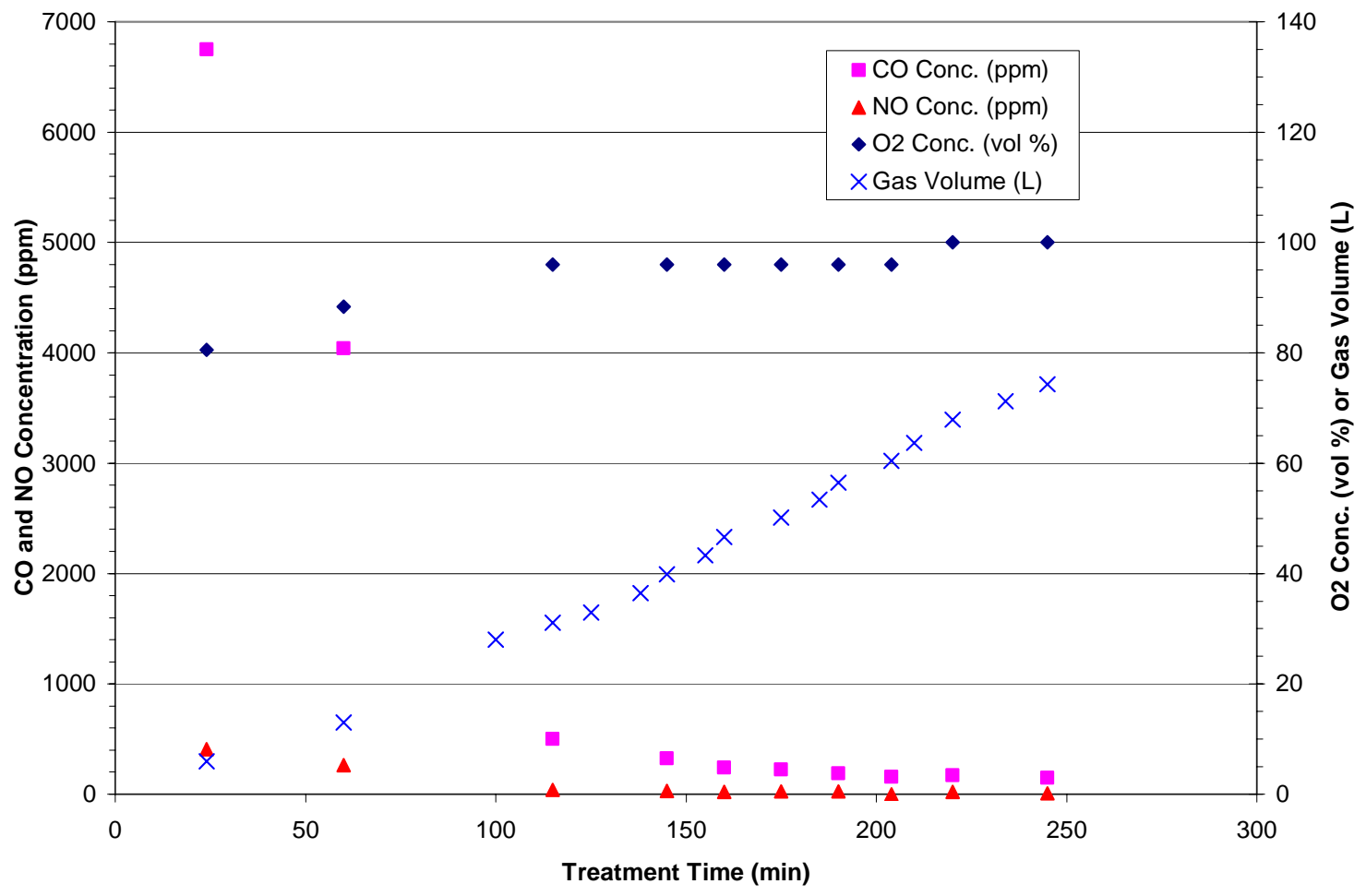

Fig. 8. Off-gas results for test 3. 
For tests 4-6, a sample of the headspace in the flask just before starting peroxide addition and hourly composite samples of off-gas were analyzed by GC for the major constituents and by GCMS for benzene and other organics. The samples for GC analysis were collected in previously evacuated stainless steel bottles, with a valve and $1 / 4$-in. tubing connection. The bottles were filled from the Tedlar bags, where the off-gas samples were composited. Air inside the 1/4-in. tubing was pulled into the sample bottle with the composite off-gas sample, so each of these samples contained a small amount of air. The volume in each bag of off-gas was measured using the syringe, and the gas was also analyzed using the emissions analyzer. The $\mathrm{O}_{2}, \mathrm{CO}$, and $\mathrm{NO}_{x}$ concentrations measured by GC and by the emissions analyzer were fairly consistent, although more scatter was present in the emissions monitor data. For tests 5 and 6, the headspace of the reaction flask and the off-gas lines were purged with argon gas just prior to collecting the last sample of off-gas. The argon purge should remove any previously generated benzene from the system, so that the benzene measured in the last sample would have been produced during the reaction of the last $20 \mathrm{~mL}$ of peroxide added. The argon concentration was measured in the final gas sample for tests 5 and 6 to determine the amount of dilution of the off-gas generated by the reaction.

Figures 9-11 show the GC results for the gas samples and the cumulative gas volumes for tests 4-6. All of the concentrations are shown as volume percent, which equals mole percent. The results were internally consistent, with the sum of the measured concentrations for each sample totaling $93-100 \%$. For each graph, the results at time $=0 \mathrm{~h}$ are for the sample from the flask headspace that was taken just prior to starting the peroxide addition. The cumulative gas volumes are plotted at the end of the composite sample period, while the concentrations are plotted at the midpoint of the composite time. The first sample from each test contains mostly air, since little off-gas had been generated during the $\mathrm{pH}$ adjustment and heating of the slurry; however, these samples also contained the highest benzene concentration, indicating that hydrolysis of the TPB was occurring.

Because of the failure and change-out of the $\mathrm{pH}$ probe, the slurry for test 5 was exposed to high temperatures for about 30 min longer before peroxide addition was started than was the case for test 4 . The benzene concentration in the initial sample from the headspace of the reaction flask was higher for test 5 than for test 4 (8.68\% vs 6.43\%); however, later samples of off-gas were higher for test 4 and the total amount of benzene in the off-gas was also higher for test 4 . The benzene results from the GC-MS analysis of the off-gas samples (described below) show much higher concentrations for all of the samples from test 5 than for the corresponding samples from test 4 . Test 6 , which used the washed simulant, showed much lower concentrations of benzene in the off-gas than for tests 4 and 5 , ranging from 0.56 to $0.02 \%$ benzene, and correspondingly higher concentrations of carbon dioxide.

The CO results for tests 4-6 from the GC analysis are shown in Fig. 12, while the $\mathrm{NO}_{x}$ results are shown in Fig. 13. 


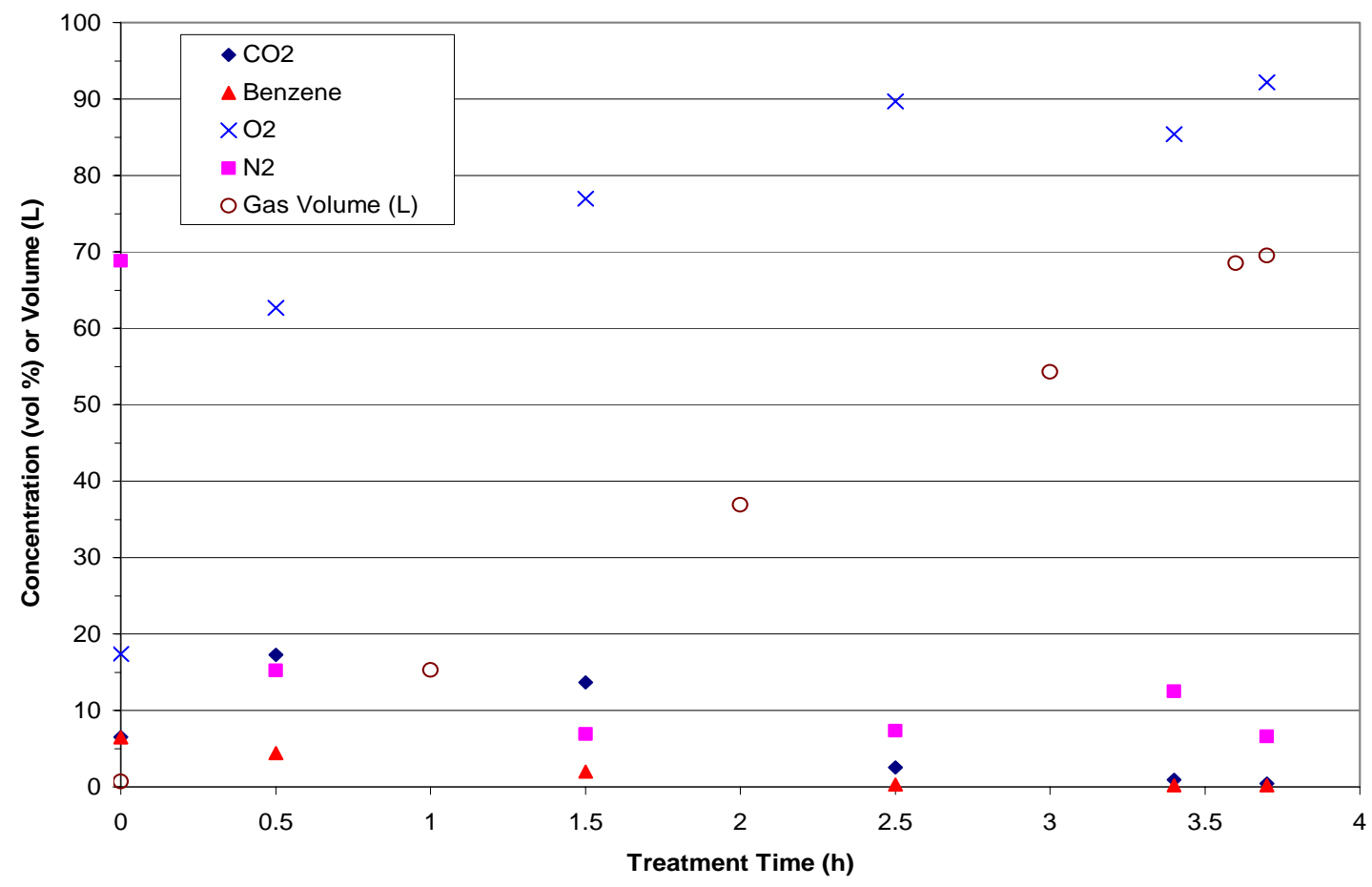

Fig. 9. Major constituents in gas from test 4, measured by gas chromatography.

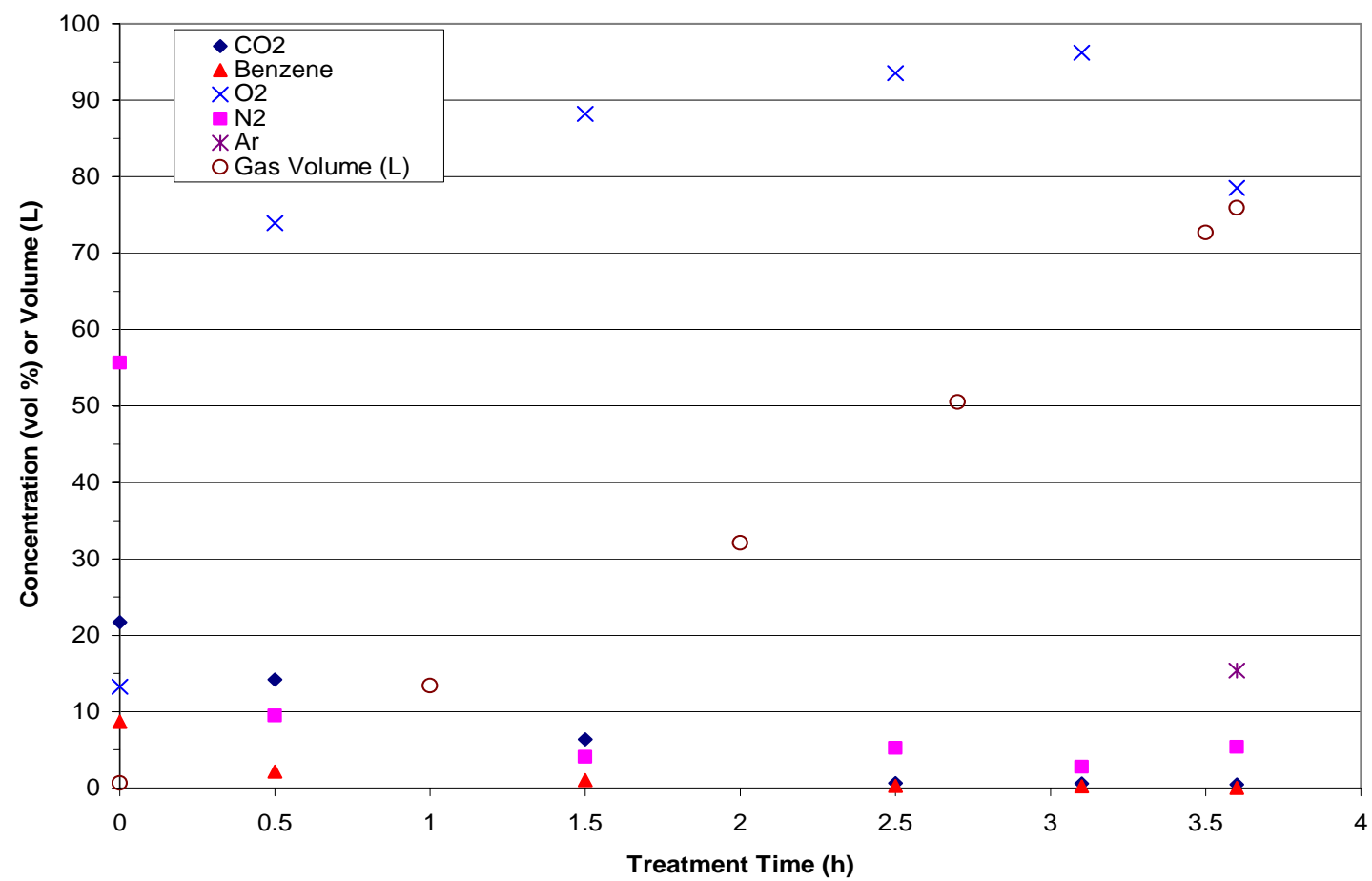

Fig. 10. Major constituents in gas from test 5, measured by gas chromatography. 


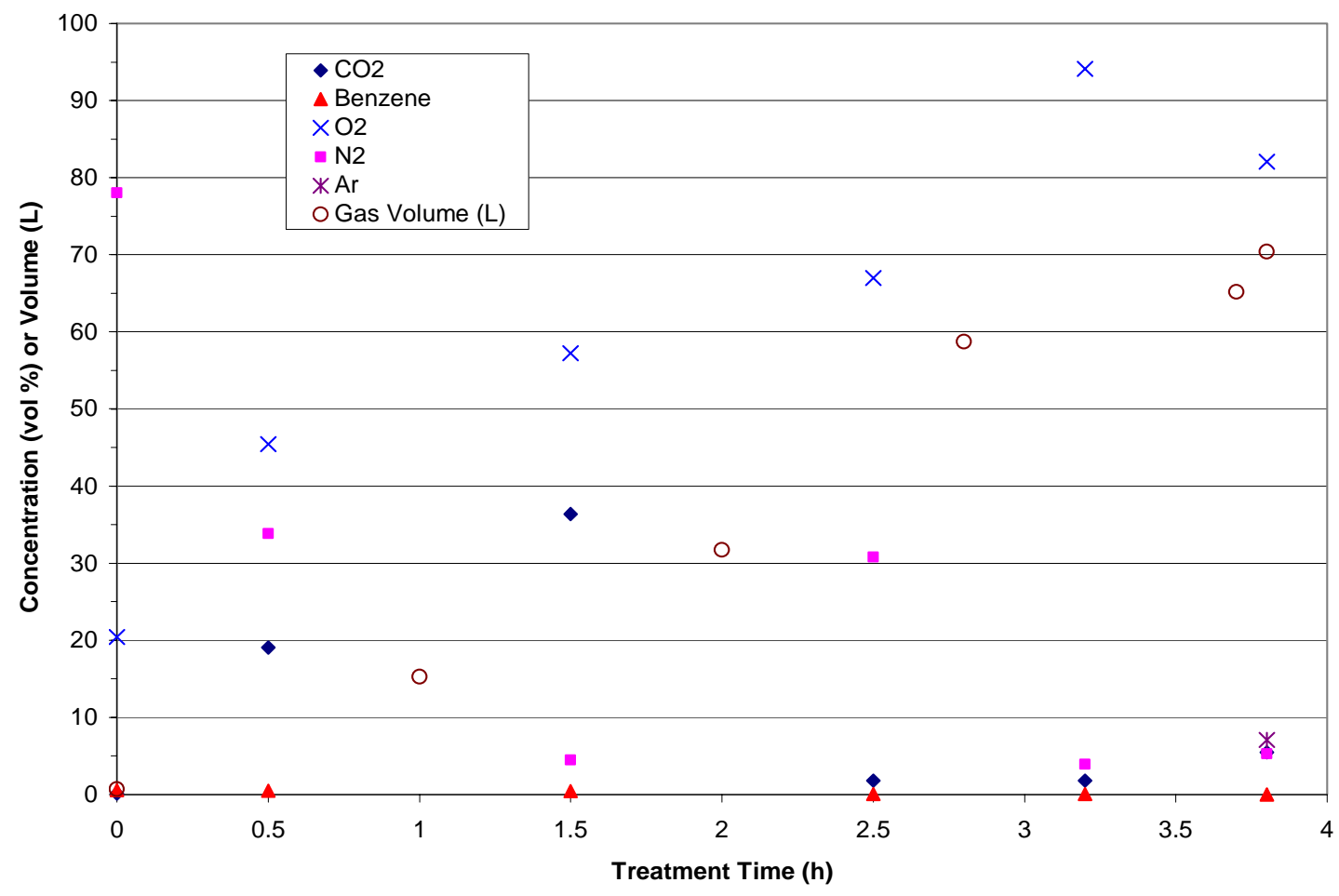

Fig. 11. Major constituents in gas from test 6, measured by gas chromatography.

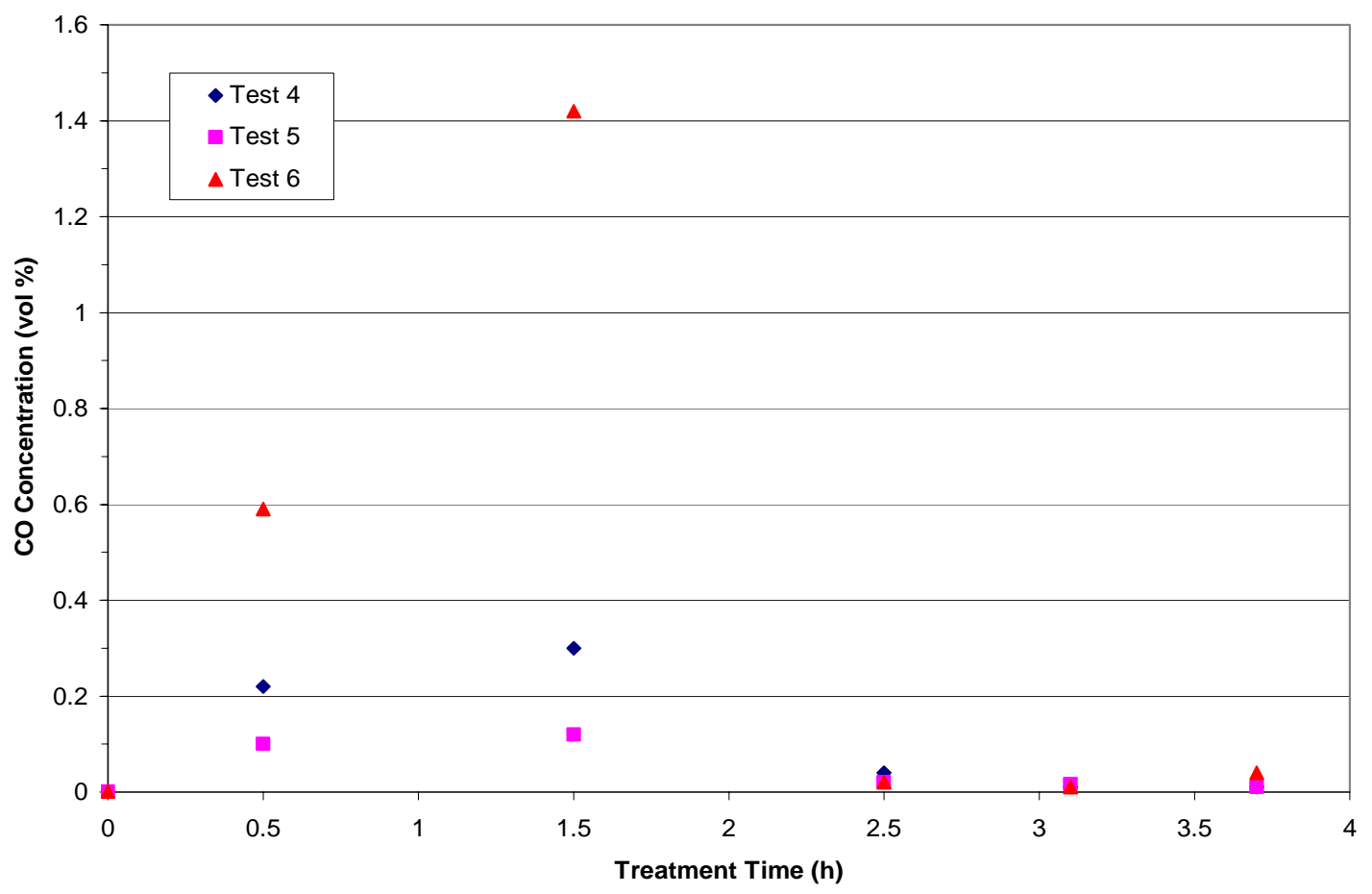

Fig. 12. CO concentrations in off-gas from tests 4-6. 


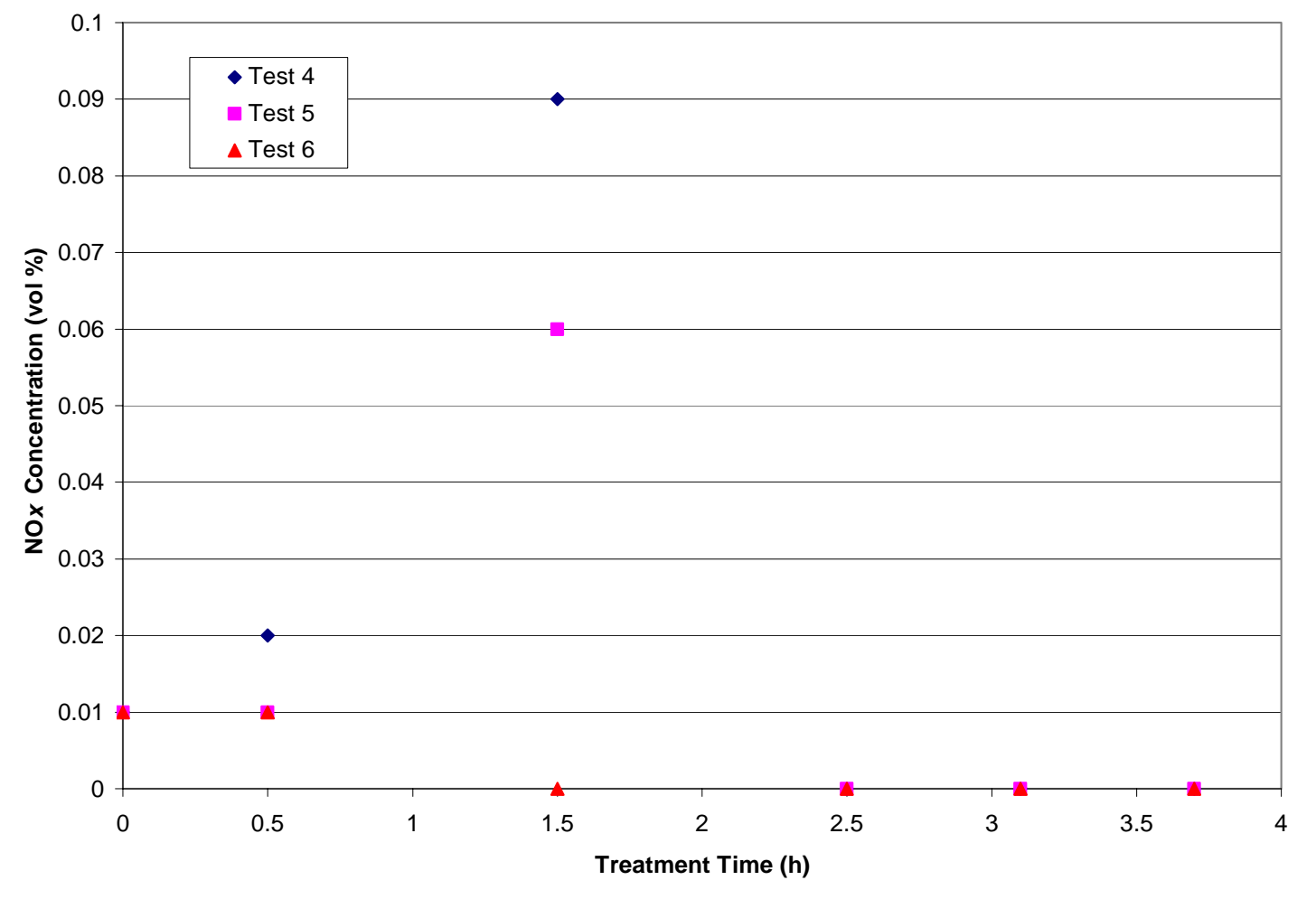

Fig. 13. $\mathrm{NO}_{x}$ concentrations in off-gas from tests 4-6.

The carbon monoxide concentrations were much higher for test 6 than for tests 4 and 5 . All of the tests showed the highest $\mathrm{CO}$ concentrations early in the treatment, when the $\mathrm{CO}_{2}$ concentrations were also highest, and then the concentrations dropped to $<0.02 \%$.

The off-gas from all three tests contained the same $\mathrm{NO}_{x}$ concentrations in the first and last three samples, and tests 5 and 6 had the same concentration for the second samples. The highest $\mathrm{NO}_{x}$ concentrations occurred just after the $\mathrm{pH}$ was reduced to 3.5. The composite samples plotted at 1.5-h treatment time contained this gas mixed with gas samples for the next hour, which contained lower concentrations of $\mathrm{NO}_{x}$. Results from the emissions analyzer for the first bag of gas ( $\sim 3 \mathrm{~L})$ generated after the $\mathrm{pH}$ was reduced to 3.5 showed NO concentrations of $0.14 \%$ for test 4 and $0.35 \%$ for test 5 . A photograph of the gas sample with the highest NO concentration is shown in Fig. 2. The washed simulant used for test 6 contained a lower concentration of nitrite than the unwashed simulant and no nitrate. This simulant produced much lower concentrations of $\mathrm{NO}_{\mathrm{x}}$ in the off-gas during treatment.

The benzene concentrations measured using GC-MS are shown in Fig. 14. The GC-MS instrument has much lower detection limits than the GC, so very small samples of the off-gas were injected to stay within the measurement range of the instrument. The small sample size reduces the precision of the measurement. The very high benzene concentration (19\%) measured in the gas sample from the headspace of the reaction flask during test 5 seems unreasonably high, but the other results are within the same range as the concentrations measured using the GC. The off-gas from test 6 showed lower benzene concentrations than those in tests 4 and 5 for both analytical techniques. 


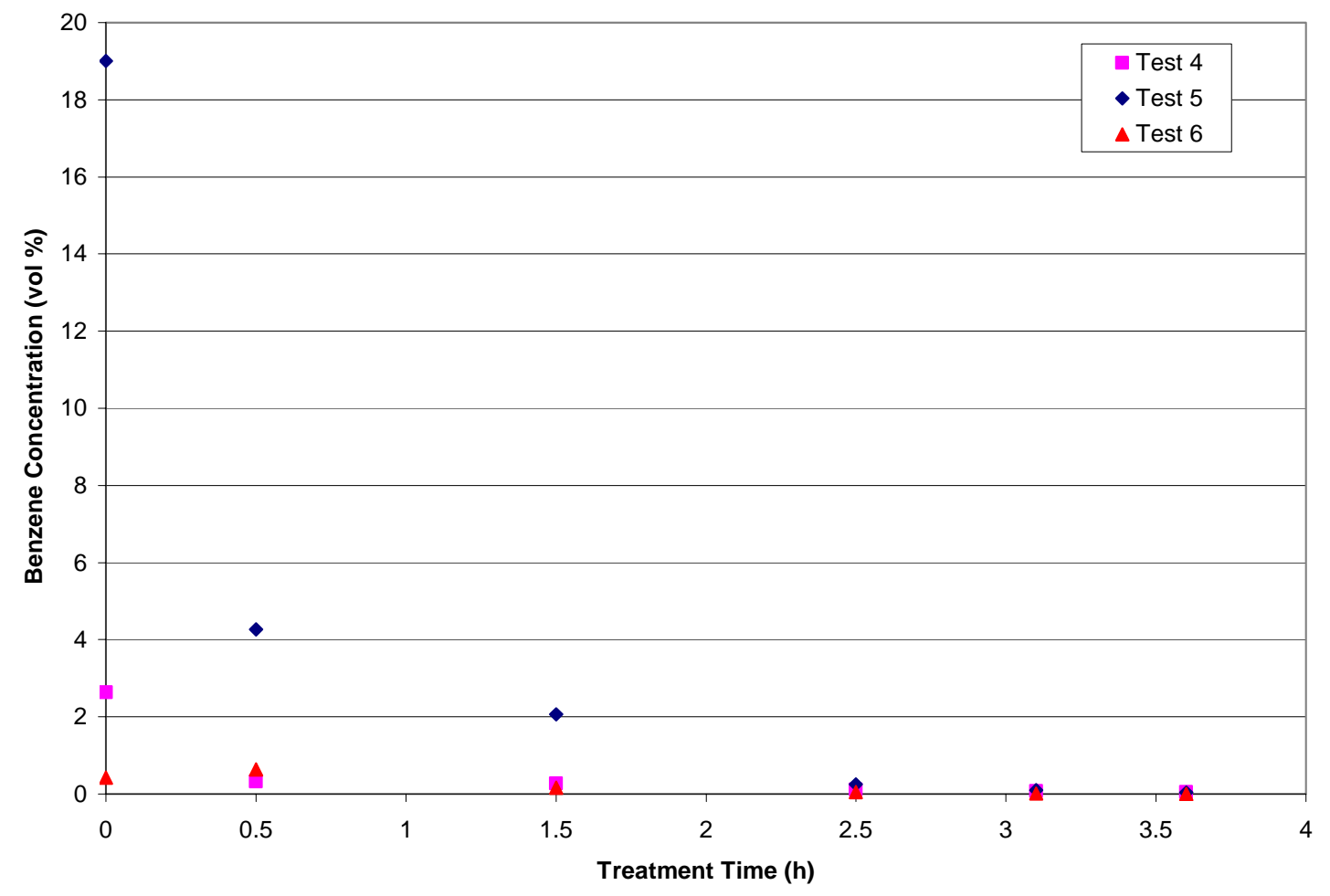

Fig. 14. Benzene concentrations in off-gas samples, measured by gas chromatography-mass spectroscopy.

Low concentrations of several other organics were detected in the off-gas samples, including acetaldehyde, acetone, nitromethane, paraldehyde, and nitrobenzene. Concentrations were highest in the early gas samples and then dropped rapidly as the treatment continued. The highest concentrations were $1600 \mathrm{ppmv}$ acetaldehyde and $400 \mathrm{ppmv}$ acetone in the early off-gas from test 6. The off-gas from tests 4 and 5 showed maximum concentrations of 190-240 ppmv acetaldehyde and 160-370 ppmv of nitromethane. For the final two samples of off-gas from all three tests, the trace organics were all below 100 ppmv.

\subsection{CARBON BALANCE}

A carbon balance for tests 4-6 was calculated from the analytical results of the treated slurry, offgas, and condenser residue for these tests. The results are shown in Table 6. The TOC results were used to calculate the amount of carbon in the treated slurry and in the residue from the condenser and off-gas line. The GC results for $\mathrm{CO}_{2}$, $\mathrm{CO}$, and benzene were used to calculate the carbon in the off-gas. The carbon in the starting simulant was calculated from the amount of TPB added, rather than using the TOC results, which were lower than expected, possibly due to hydrolysis of the TPB during drying of the samples. 
Table 6. Carbon balance for tank $48 \mathrm{H}$ treatment tests

\begin{tabular}{lccc}
\hline \multirow{2}{*}{ Description of Source } & \multicolumn{3}{c}{ Moles of Carbon } \\
\cline { 2 - 4 } Benzene in off-gas & 0.365 & Test 5 & Test 6 \\
CO $_{2}$ in off-gas & 0.302 & 0.193 & 0.055 \\
CO in off-gas & 0.005 & 0.168 & 0.502 \\
TOC in slurry & 0.002 & 0.002 & 0.017 \\
Off-gas deposits & 0.011 & 0.002 & 0.001 \\
\hline Total & 0.685 & 0.004 & 0.011 \\
Starting simulant & 0.873 & 0.369 & 0.586 \\
Recovery (\%) & 78.5 & 0.873 & 0.873 \\
\hline
\end{tabular}

If the benzene results from the GC-MS analysis are used in place of the GC results, the amount of carbon in the off-gas due to benzene changes to 0.042 mol for test 4 and $0.303 \mathrm{~mol}$ for test 5 , and the carbon recovery changes to 41.6 and $55.2 \%$, respectively. The increased benzene concentration measured by the GC-MS in the first two composite off-gas samples for test 5, rather than the very high concentration measured in the headspace sample, is the main contributor to the increased amount of carbon in the off-gas, since the headspace sample represents a low gas volume. The results for test 6 do not change significantly if the GC-MS results are used.

\section{CONCLUSIONS}

Fenton's reagent was very effective in destroying the TPB in simulants of the Tank $48 \mathrm{H}$ waste. A series of tests were completed using treatment parameters suggested by AEA Technology. The treated samples contained low concentrations of TOC and no detectable TPB. Tests using a mixture of iron and copper salts as the Fenton's catalyst had a lower TOC concentration in the final treated slurry than did tests that used a copper-only catalyst, results that are opposite to those reported by AEA. TPB is known to hydrolyze to benzene - particularly at high temperature and low $\mathrm{pH}$ in the presence of metal catalysts, such as $\mathrm{Cu}, \mathrm{Pd}$, and Hg. Significant amounts of benzene were present in the off-gas from the tests, especially during the early portion of the treatment, indicating that the hydrolysis reaction was occurring in parallel with the oxidation of the TPB by Fenton's reagent. For the reaction conditions used in these tests, approximately equal fractions of the TPB were converted to benzene and carbon dioxide. Minimizing the formation of benzene is important to SRS personnel; however, this consideration was not addressed in the AEA-recommended parameters, since they did not analyze for benzene in the off-gas. It is expected that using only iron for the Fenton's catalyst and starting peroxide addition at a lower temperature would promote the Fenton's reaction over the hydrolysis reaction, producing more carbon dioxide and less benzene; however, this variation has not yet been tested. Smaller amounts of carbon monoxide and other organics were also produced. One test used a simulant with much lower concentrations of salts, representing washed sludge, and this test produced much lower amounts of benzene. The nitrite ions in the simulant were oxidized to nitrate, which would increase the amount of peroxide required to oxidize all of the organic carbon. Oxygen is the primary constituent of the off-gas from treating the samples. 


\section{REFERENCES}

1. H. J. H. Fenton, “Oxidation of Tartaric Acid in the Presence of Iron,” J. Chem. Soc., 65, 899 (1894).

2. F. K. Newheiwat and A. G. Swanson, "Clean Contaminated Sites Using Fenton’s Reagent,” Chem. Eng. Prog., 96, 61 (2000).

3. P. A. Taylor, Destruction of Ion-Exchange Resin in Waste from the HFIR, T1, and T2 Tanks Using Fenton's Reagent, ORNL/TM-2002/197, Oak Ridge National Laboratory, Oak Ridge, TN, October 2002. 



\section{INTERNAL DISTRIBUTION}

1. J. N. Herndon

2. B. E. Lewis

3. C. P. McGinnis

\author{
4-6. P. A. Taylor \\ 7. ORNL Laboratory Records-RC, \\ CRL, OSTI
}

\section{EXTERNAL DISTRIBUTION}

8. C. C. Canada, Westinghouse Savannah River Company

9. D. T. Conrad, Westinghouse Savannah River Company

10. S. D. Fink, Westinghouse Savannah River Company

11. A. P. Giordano, Westinghouse Savannah River Company

12. J. C. Griffin, Westinghouse Savannah River Company

13. H. D. Harmon, Pacific Northwest National Laboratory

14. D. P. Lambert, Westinghouse Savannah River Company

15. C. E. Miller, DOE-HQ

16. T. B. Peters, Westinghouse Savannah River Company

17. B. C. Rogers, Westinghouse Savannah River Company

18. R. H. Spires, Westinghouse Savannah River Company

19. P. C. Suggs, DOE-SRS 